\title{
The Role of Proteomics in Elucidating Multiple Antibiotic Resistance in Salmonella and in Novel Antibacterial Discovery
}

\author{
Rui Pacheco ${ }^{1-4^{* *}}$, Susana Correia ${ }^{1-4^{* *}}$, Patrícia Poeta ${ }^{3,4}$, \\ Luís Pinto1-4 and Gilberto Igrejas ${ }^{1,2,}{ }^{*}$ \\ ${ }^{1}$ Institute for Biotechnology and Bioengineering, Center of Genomics and Biotechnology \\ University of Trás-os-Montes and Alto Douro \\ ${ }^{2}$ Department of Genetics and Biotechnology, University of Trás-os-Montes and Alto Douro \\ ${ }^{3}$ Center of Studies of Animal and Veterinary Sciences \\ ${ }^{4}$ Veterinary Science Department, University of Trás-os-Montes and Alto Douro \\ Portugal
}

\section{Introduction}

Salmonellae are Gram-negative facultative anaerobes that have been divided into two species: S. enterica, which is subdivided into over 2,500 serovars, and Salmonella bongori. Some serovars of $S$. enterica, such as $S$. Typhi, cause systemic infections and typhoid fever, whereas others, such as $S$. Typhimurium, cause gastroenteritis. Nontyphoidal Salmonella are a major cause of food poisoning being Salmonellosis one of the most common and widely distributed foodborne diseases. Millions of human cases are reported worldwide every year and the disease constitutes a major public health burden, causing significant morbidity and mortality in several countries. Since the beginning of the 1990s, strains of Salmonella which are resistant to a range of antimicrobials, including first-choice agents for human treatment, have emerged and are threatening to become a serious public health problem. Multidrug-resistant strains of Salmonella are now frequently encountered and the rates of multidrug-resistance (MDR) have been increasing considerably in recent years [World Health Organization (WHO, 2005)].

Strains of Salmonella spp. with resistance to antimicrobial drugs are now widespread in both developed and developing countries. Effective antimicrobial agents are essential for human and animal health and welfare. However, infections caused by resistant microorganisms often fail to respond to standard treatment, resulting in prolonged illness and greater risk of death. Hence, the increasing antimicrobial resistance is considered a public health problem at a global level (Musgrove et al., 2006; Võ, 2007). A diversity of foods and environmental sources harbor bacteria that are resistant to antimicrobial drugs used in medicine and in food-animal production (Bager \& Helmuth, 2001; Schroeder et al., 2004). Also the misuse

\footnotetext{
${ }^{*}$ Corresponding author

${ }^{*}$ Both authors contributed equally to this work
} 
and/or excessive use of antibiotics in human and veterinary medicine are in certain cases responsible for the increase and spread of resistance seen among the bacterial population. Antimicrobial agents are known to be clinically prescribed in situations where there is no bacterial infection or the illness event is a viral infection. In other cases, the treatment of an infection is made with the incorrect antibiotic combinations, doses or durations that are sometimes excessive. Antimicrobial resistance reduces the effectiveness of treatment as patients remain infected for longer, thus potentially spreading resistant microorganisms to others. The achievements of modern medicine are also at risk since, without effective antimicrobials for care and prevention of infections, the success of treatments such as organ transplantation, cancer chemotherapy and major surgery would be compromised. In addition, the growth of global trade and travel allows resistant microorganisms to be spread rapidly to distant countries and continents; this represents a threat to health security, and damages trade and economies (WHO, 2011).

Bacterial antibiotic resistance can be classified in five different main mechanisms, involving the antibiotic molecules or its targets in the cell (Figure 1).

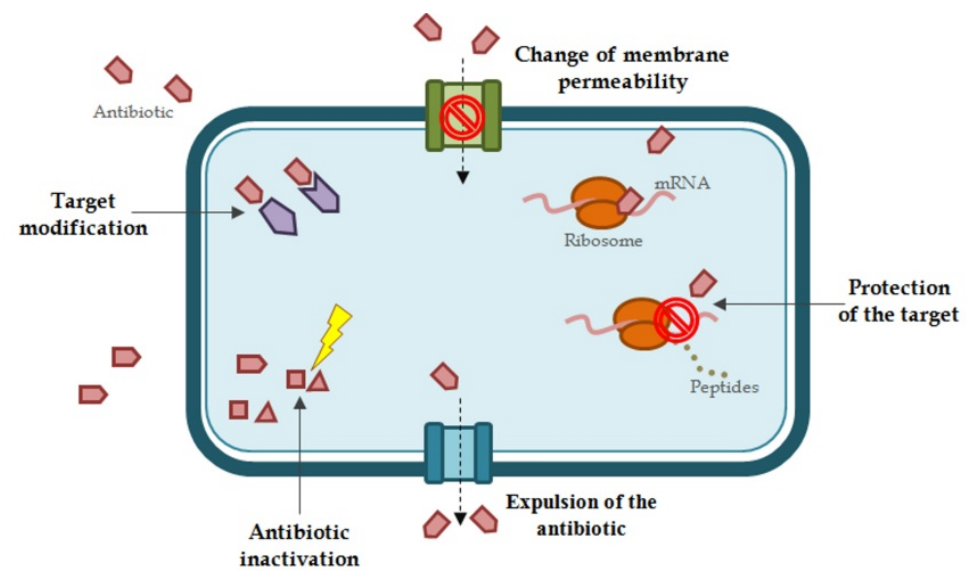

Fig. 1. Antibiotic resistance mechanisms. Adapted from Yao \& Moellering, 2003. Antibacterial Agents American Society for Microbiology, Washington.

Although genes encoding efflux pumps can be found on plasmids, the carriage of efflux pump genes on the chromosome gives the bacterium an intrinsic mechanism that allows survival in a hostile environment (e.g. the presence of antibiotics), and so mutant bacteria that over-express efflux pump genes can be selected without the acquisition of new genetic material (Webber \& Piddock, 2003). Before the development of genomics, the scientific community focused investigations on single or small groups of genes or proteins. The genome-sequencing projects of the late 1990's yielded entire genome sequences of many bacteria, leading to a large amount of genetic data. These new platforms of the so-called "omic" technologies allow the analysis and characterization of biological systems and promised to facilitate our understanding of normal cellular function and dysfunction by permitting simultaneous monitoring of thousands of molecular components. There are currently 1587 complete bacterial genomes and 4901 bacterial genomes in-progress at NCBI (http://www.ncbi.nlm.nih.gov/genomes/lproks.cgi). Even though the number of encoding 
entities (open reading frames, ORFs) can be predicted from the genome, the number of different proteins that an organism is capable of generating cannot directly be deduced - a global protein analysis is needed to define the protein composition of a given cell under a certain circumstance (Brotz-Oesterhelt et al., 2005).

Proteomics, defined as the global analysis of cellular proteins, is a key area of research that is developing in the post-genome era (Osman et al., 2009). The term proteome, in analogy to the term genome, was coined to describe the complete set of proteins that an organism has produced under a defined set of conditions (Wasinger et al., 1995). In the last few years proteomics has become a powerful tool for the investigation of complex biochemical processes, the discovery of new proteins and investigation of protein-protein interactions. The proteome is highly dynamic and much more complex than the genome - the number of encoding entities can be predicted from the genome, but the number of different proteins that an organism is capable of generating cannot be directly deduced. Hence, a global protein analysis is needed to define the protein composition of a given cell under a specific circumstance (Brotz-Oesterhelt et al., 2005). Moreover, the evaluation of protein profiles in response to multiple stress mechanisms, such as sensitivity to antibiotics or modifications related to antibiotic resistance, could represent a valid and integrating approach for the development of new therapeutic strategies. In complement, Mass Spectrometry (MS)-based proteomics and bioinformatics were shown to be suitable for evaluation of the effect of protein extracts, whole cell versus outer membrane proteome (OMP), on the identification of Gram-negative organisms. Different numbers of distinguishing, unique proteins were obtained by the bioinformatics procedure between the two protein extraction methods.

This chapter will present an overview of the major achievements of proteomic approaches to study Salmonella and its adaptation networks that are crucial for bacteria. Furthermore the published efforts to exploit the knowledge derived from the proteomic studies directly for the antibacterial drug discovery process will be reviewed. Special focus will be placed on antibiotic treatment induced stress and particular stressful environments. Finally, recent developments related to the Salmonella proteome and technological determinants used as biomarkers will be discussed.

\section{Proteomics in practice}

In the mid-1990's, two factors arose that substantially simplified proteomic analysis. For the first time, DNA sequences of whole bacterial genomes became available and allowed the prediction of the approximate total number of encoded ORFs (Brotz-Oesterhelt et al., 2005). At the same time, progress in MS facilitated the analysis of peptides and small proteins, and the accuracy of the measured peptide masses was sufficient to allow protein identification. The introduction of user-friendly, browser-based bioinformatics tools to extract information from these databases constituted a key of the post-genomic era. It is now possible to search entire genome sequences for specific nucleic acid or protein sequences to have a global view of living organisms through in silico analysis. Proteome informatics tools span today a large panel of very diverse applications ranging from simple tools to compare protein amino acid compositions to sophisticated software for large-scale protein structure determination (Palagi et al., 2006). The application of proteomics provides major opportunities to elucidate disease mechanisms and to identify new diagnostic markers and therapeutic targets. Significant progress has been made in the characterisation of bacterial pathogens using a 
combination of genomic and proteomic technologies. Pathogenic determinants are identified through comparative proteomics between virulent and avirulent isolates whereas complex disease phenotypes can be correlated with specific proteomic signatures identified through the analysis of large collections of natural isolates (Osman et al., 2009).

Proteomics is used to describe any large-scale investigation of proteins and can be approached in many ways but in principle it consists in three steps (Figure 2): (1) protein extraction, (2) separation and (3) identification. Most of the approaches require MS and database searching for protein identification but differ in the way the proteins are separated and isolated (Westermeier \& Naven, 2002). In the extraction process, depending on the source, the proteins have to be brought into solution by breaking the tissue or cells containing them. Several methods like repeated freezing and thawing, sonication, homogenization by high pressure, filtration, or permeabilization by organic solvents are used to achieve this purpose. The methodology used depends on how fragile the protein is and how sturdy the cells are.

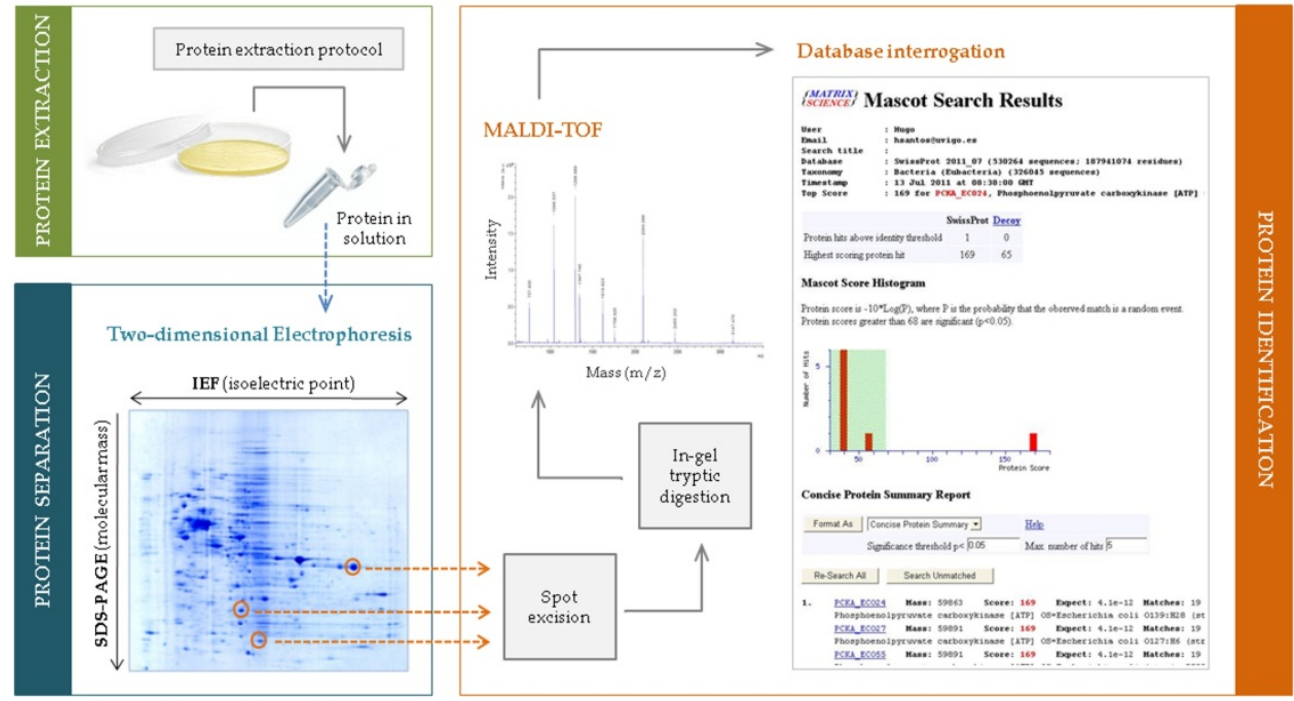

Fig. 2. Typical proteomic workflow representing the classical components of protein identification. Proteins are extracted and then separated according to isoelectric point and molecular mass (two-dimensional gel electrophoresis, 2-DE). Spots of interest are excised, digested and then proteins are identified by MS followed by data interrogation against genomic or proteomics databases using bioinformatic tools.

One of the most important ways that proteins are separated is by electrophoresis, including two-dimensional gel electrophoresis (2-DE) and capillary electrophoresis (Mishra, 2010). The latter involves the separation of proteins and peptides carried in a thin glass tube under high voltage before injection into the mass spectrometer for their identification. Thin tubes have the advantage of dissipating heat by high voltage, and separated proteins can be visualized and monitored by ultraviolet (UV) light during the eletrophoretic run. However, protein separation by 2-DE is the most commonly used method in proteomics. Proteins are separated according to isoelectric point (pI) in the first dimension and to molecular mass $(\mathrm{Mr})$ in the 
second. The gels are stained to visualize the resolved proteins using a dye that can contain zinc or copper, Coomassie Blue, silver or a fluorescent dye (Mishra, 2010). Zinc or copper staining is a negative staining because it stains the gel and not the protein spots; this method is inexpensive and has a sensitivity to detect spots containing 6-12 ng of protein, but it has difficulty in handling thin gels. Coomassie Blue is an easy and an inexpensive stain that is used to identify proteins by mass spectrometry; it has a sensitivity of 36-45 ng of protein per spot in the gel. Silver staining is expensive and time consuming but with high sensitivity as it can detect 0.5-1.2 ng of protein per spot in the gel. 2D Differential Gel Electrophoresis (DIGE) is a modification of 2D gel electrophoresis to avoid any differences that are usually encountered when samples are run on different gels even under identical conditions. In this method, multiple protein samples are separately labelled with different fluorescent dyes and then coelectrophoresed on the same 2-DE gel. Fluorescent dyes come in a variety of choices; they are quick and easy to use and are highly sensitive like silver staining but not compatible to subsequent techniques of protein identification by MS (Mishra, 2010).

After staining, the spots of interest are excised, either manually or automatically. An in-gel tryptic digestion of the gel spot is conducted and the protein is identified by MS analysis of the resultant peptides followed by data interrogation against genomic or proteomics databases using bioinformatic tools. This technique was initiated by Stegemann (1970) (as cited in Westermeier \& Naven, 2002), combining isoelectric focusing (IEF) and SDS polyacrylamide gel electrophoresis (SDS-PAGE). 2-DE resolution was considerably increased when O'Farrell, in 1975, introduced denaturating conditions during sample preparation and IEF. This modification gave wide acceptance to the method but the technique only became reproducible enough for proteome analysis in 1982, with the application of immobilized $\mathrm{pH}$ gradients for the first dimension (Bjellqvist et al., 1982). 2DE/MS provides a direct method to separate proteins and to visualize changes between complex proteome samples and it is able to resolve thousands of proteins. Many technological improvements have made 2-DE relatively inexpensive and accessible to most biomedical research labs but criticisms such as the inability of 2D-PAGE to resolve membrane proteins and its lack of reproducibility have been to some extent tempered by the development of better reagents, techniques, and gel alignment software. Even though 2-DE is still limited in sensitivity and dynamic range (Veenstra, 2007), it is still the most widely used method for protein separation. Nonetheless, liquid chromatography methods which includes gel filtration, affinity chromatography, ion exchange chromatography, ReversePhase (RP) and High-Performance Liquid Chromatography (HPLC), and multidimensional chromatography are also used for protein separation in proteomic analysis (Mishra, 2010).

For protein identification one can use an approach that is not based on spectrometry (determination of the amino acid sequence from the DNA sequence or the identification of one amino acid at a time from the N-terminus of the peptide - Edman Degradation) or a MS approach which allows protein identification based on their amino acid sequence (Mishra, 2010). Peptide mass fingerprinting (PMF) is the easiest and fastest way to identify proteins (Westermeier \& Naven, 2002). In this method, the protein of interest is digested with a proteolytic enzyme, commonly trypsin, inside a gel plug and the cleavage products (peptides) are eluted and submitted to MS analysis. MALDI-TOF (Matrix-assisted laser desorption/ionization - Time-of-flight) instruments are preferably used because they are easier to handle than electrospray systems (ESI-TOF). The mass spectrum with the accurately measured peptide masses is matched with theoretical peptide spectra in various 
databases using adequate bioinformatic tools. Even though this procedure works very well for protein identification, the method can be compromised for several reasons. In these circumstances, more specific information is needed for unambiguous protein identification and so the amino acid sequence is determined. During MS analysis a peptide can be selected from the spectrum and fragmented inside the instrument, termed tandem MS (MS/MS). The resultant fragment ion masses are indicative of amino acid sequence that can be used to search not only protein databases but also Expressed Sequence Tag (EST) databases and used for de novo sequencing when necessary.

The evolution of MS-based proteomic technologies has advanced our understanding of the complex and dynamic nature of proteomes while simultaneously revealing that no proteomic strategy can be used alone to address all biological questions. Figure 3 depicts a typical proteomic workflow with examples of commonly used techniques that may be

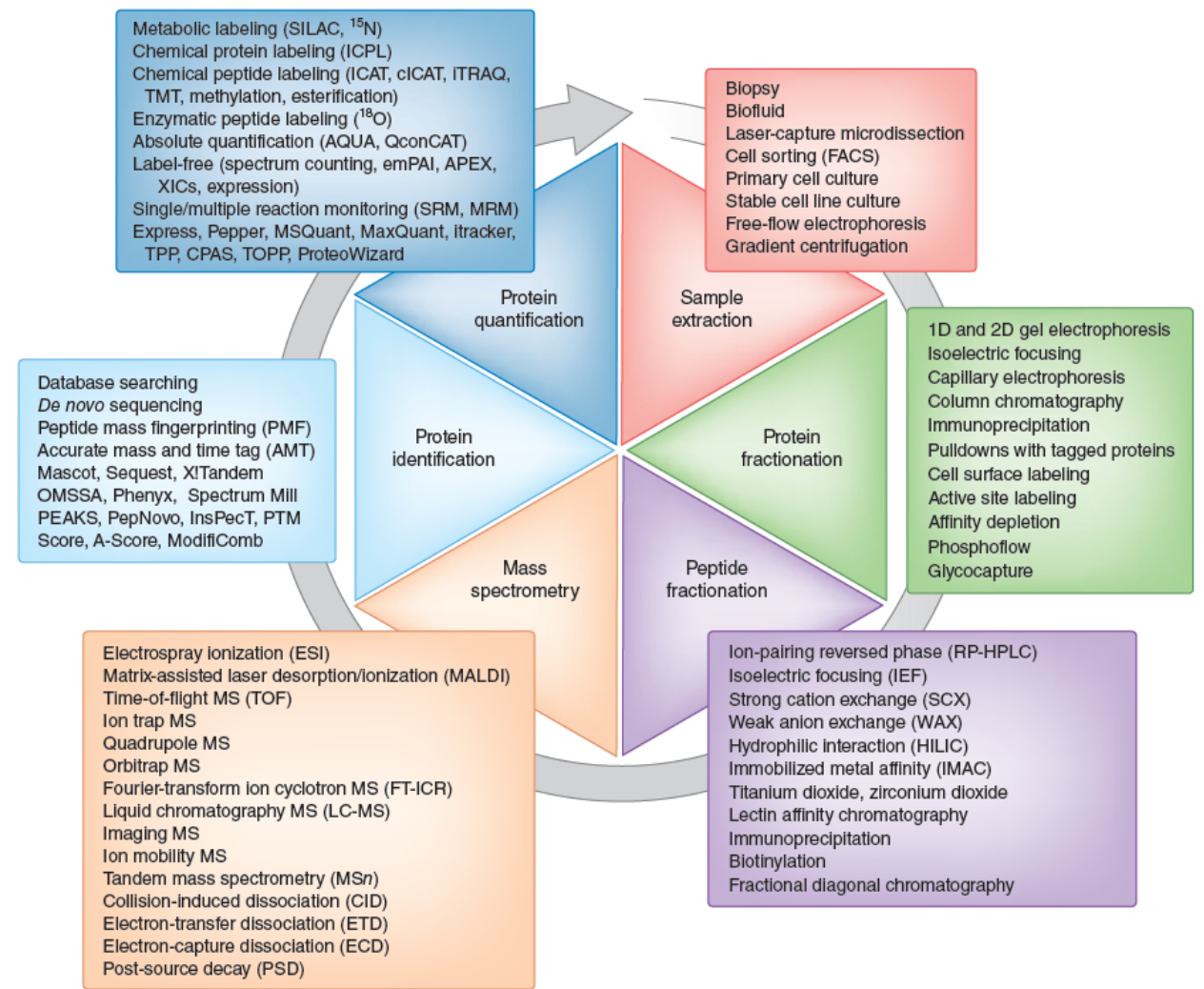

Fig. 3. Technologies for proteomics. This figure depicts the proteomic workflow from sample extraction to protein quantification. For each step in the workflow, the text boxes give examples of commonly used techniques, many of which may be combined in any one study. Reprinted by permission from Macmillan Publishers Ltd: [Nature Biotechnology] (Proteomics: A Pragmatic Perspective., 28(7): 695-709), copyright (2010) (Mallick \& Kuster, 2010). 
applied in most types of proteomics studies. Several tools are available to help quantify and interpret data generated through specific applications of MS. MS-based quantitative approaches include tagging or chemical modification methods, such as isotope-coded affinity tags (ICAT), isobaric tag for relative and absolute quantitation (iTRAQ) or stable isotope labelling by amino acids in cell culture (SILAC). A further detailed description of proteomic techniques can be consulted in Hamacher et al., 2011; Mallick \& Kuster, 2010; Mishra, 2010; Parker et al., 2010; Veenstra, 2007; Westermeier \& Naven, 2002.

Despite the variation in proteomics approaches, all techniques generate large quantities of data. Bioinformatics approaches appear as an essential mean for analysis, storage and retrieval of all that information. In 2-DE, there are several software available for image analysis that allow the comparison of different gels. 2-DE gels are not exactly identical; different factors may cause variation between analysis, such as preparation methods, staining, and unequal mobility in the different gels' regions and variations in electrophoretic conditions, even when studying the same sample. Automatic gel matching methods include features like spot detection, gel warping and auto-matching; this matching is the starting point for deeper analysis and statistical studies. Through MS, integrated systems allow protein identification, based on comparison of peptide fingerprints with proteins in databases (Vihinen, 2003). Bioinformatics not only helps the interpretation of results but it also may guide the course of new investigations since results and new discoveries from laboratories from all over the world can be stored in online databases, available to any researcher.

Due to the wide diversity of proteins and properties in complex proteomes, it is anticipated that no single proteome analysis technology will be able to effectively address all proteome analysis requirements. 2-DE gels will probably remain the "gold standard" within the foreseeable future to which any competing method should be compared, and to which it should display clear advantages of 2-DE with IPGs (Görg et al., 2009). In contrast to the 2$\mathrm{DE}$ approaches, information about protein abundances is initially unavailable in the nongel-based technologies, unless stable isotope labelling is applied. Moreover, 2-DE is highly parallel and unsurpassed for its ability to run as far as 202 -D gels at a time with thousands of proteins per gel. Post-translationally modified (PTM) proteins can be readily located in 2DE gels because they appear as distinctive spot clusters, which can be subsequently identified by MS analysis. For a global view, post-translational modifications (PTMs) (e.g. glycosylation or phosphorylation) can be visualized with specific fluorescent dyes (Hecker et al., 2008; Zong et al., 2008). However, there are challenges, in particular, with respect to detection of low-abundance proteins and, particularly, of integral membrane proteins, whereas non-gel-based methods are unsurpassed by their potential to cover the whole proteome (de Godoy et al., 2008).

\section{Antimicrobial resistance in Salmonella}

An alarming increase in the incidence of antibiotic resistant strains of Salmonella was pointed out by the World Health Organization more than 20 years ago (Brisabois et al., 1997). Multiple antibiotic resistance in Salmonella has also been increasing; about $45 \%$ of the isolates of Salmonella Typhimurium reported to the Enter-net surveillance network in recent years presented a MAR phenotype (International surveillance network for the enteric infections Salmonella and VTEC O157, 2008). 
Salmonella commonly show resistance to ampicillin, chloramphenicol, streptomycin/ spectinomycin, sulphonamides and tetracyclines (R-type ACSSuT), with additional resistance to third-generation cephalosporins mediated by the CMY-2 beta-lactamase gene (Antunes et al., 2006; Threlfall, 2002; Threlfall, 2008). The increasing number of infections with R-type ACSSuT Salmonella, with extended-spectrum B-lactamase (ESBL)-producing Salmonella and with quinolone-resistant Salmonella strains, have emerged as a global health problem and deserve special attention (Antunes et al., 2006; Threlfall, 2008).

Infections due to antibiotic-resistant Salmonella may have different consequences. People treated with antimicrobial drugs for unrelated reasons, such as upper respiratory tract infections, are at increased risk of infection with Salmonella that are resistant to the given antibiotic. Infections by resistant Salmonella have been proven to be more severe than infections with susceptible strains and resistance is directly associated with increased frequency of treatment failures, mainly when there is a prolonged duration of illness, associated with increased hospitalization (WHO, 2005).

The emergence of MDR Salmonella strains with resistance to fluoroquinolones and thirdgeneration cephalosporins is also a serious development, which results in severe limitation of the possibilities for effective treatment of human infections. Ceftiofur and ceftriaxone are two of the most common antimicrobials used for treatment of infections caused by Salmonella, especially invasive ones, but there are already records of strains containing the bla $a_{\mathrm{CMY}-2}$ cephalosporine-resistance gene (Dunne et al., 2000; Fey et al., 2000; Winokur et al., 2000). The concern rises from the fact that third generation cephalosporins are drugs of choice in invasive infections caused by strains with resistance to ciprofloxacin (Threlfall, 2002). Also, mobile genetic elements allow and have been associated to resistance transmission as they may contain one or more resistance-associated genes (White et al., 2001). This spread of resistances has led to a predominance of resistant strains in several countries. In the United States of America, United Kingdom, France and Germany, the predominant Salmonella type is resistant to at least five drugs: ampicillin, chloramphenicol, streptomycin, sulfonamides and tetracycline (Helms et al., 2002).

While resistance to fluoroquinolones often emerges as a result of mutations in the bacterial genome (DNA), resistance to other antimicrobials often spread by DNA transfer between bacterial strains through plasmids. Nalidixic acid was the first quinolone antibacterial agent licensed for use in the United States. Since introduction of nalidixic acid in the 1960s, subsequent generations of fluoroquinolones have been licensed by the US Food and Drug Administration (FDA). Fluorination of quinolone compounds resulted in the introduction of norfloxacin in 1986 and ciprofloxacin in 1987, followed by other second-generation fluoroquinolones. Additional modifications resulted in third- and fourth-generation fluoroquinolones. Some fluoroquinolones are no longer available, and others are of limited use clinically. Currently, ciprofloxacin, levofloxacin, gatifloxacin, and moxifloxacin are the most widely used fluoroquinolones. When fluoroquinolones were first licensed for human therapy, no immediate rise in Salmonella resistance was observed (WHO, 2005). In contrast, when fluoroquinolones were subsequently licensed for use in food animals, the rates of fluoroquinolone-resistant Salmonella in animals and food, and then subsequently in human infections, rapidly increased in several countries (WHO et al., 2003). Even worse than the increasing rates of drug-resistant Salmonella is the fact that some variants of Salmonella have developed MDR as an integral part of the genetic material of the organism, and are therefore 
likely to retain their drug-resistant genes even when antimicrobial drugs are no longer used, a situation where other resistant strains would typically lose their resistance (WHO, 2005).

Evidence from many countries supports the role of agricultural antimicrobial use and increasing prevalence of resistance among commensal and pathogenic bacteria isolated from food animals, humans, the food supply, and the environment. First, a mass flow concept of antimicrobial pressure and resistance evolution supports the importance of controlling the agricultural use of antimicrobials because this is the primary category of use worldwide; and second, the problem must be redefined as one of resistance and gene flow, thus challenging the basis of policies that respond to or prioritize specific drug/bug combinations (Silbergeld et al., 2008). In developed countries the existence of Salmonella organisms resistant to antibiotics is an almost inevitable consequence of the use of antimicrobial drugs in food-producing animals. Although legislation targeted at controlling the overall usage of antimicrobials in livestock, in recent years there have been significant increases in the occurrence of resistance in non-typhoidal Salmonella. Selective pressure from the use of antimicrobials in food animals may be a major driving force behind the emergence of resistance but other factors must also be considered; some Salmonella serotypes are more prone to develop resistance than others and major shifts in the occurrence of Salmonella serotypes in food animal and humans are regularly seen. An example is the global spread of a multidrug-resistant $S$. Typhimurium phage type DT104 in animals and humans that may not only have been facilitated by the use of antimicrobials, but also worsened by international and national trade of infected animals.

In the past, studies on Salmonella isolates from human infection cases and clinical animal samples showed low resistance levels (Seyfarth et al., 1997). Nevertheless, it has been shown that the occurrence of resistant Salmonella strains in domestic animals is associated with the continuing use of antimicrobial agents in animal herds (van Leeuwen et al., 1979; Threlfall et al., 1993, as cited in Seyfarth et al., 1997). The routine practice of giving antimicrobial drugs to domestic livestock as a mean of preventing and treating diseases, as well as promoting growth, is an important factor in the emergence of antibiotic-resistant bacteria that are subsequently transferred to humans by the food chain (Angulo et al., 2004, as cited in Miko et al., 2005). Even indirect contact between animals, humans and ecosystems may lead to the transference of bacteria and/or resistance genes from one microorganism to another (Radhouani et al., 2010), making resistant Salmonella strains a cross-species problem. Hence, the emergence and dissemination of antimicrobial-resistant pathogens such as Salmonella has become a serious health hazard worldwide. The comparison between the genomes of different serovars revealed that despite their similarities, each serovar has many insertions and deletions in relation to the others, which vary in size from 1 to $50 \mathrm{kB}$ (Edwards et al., 2002). However, the observed differences at the DNA level proved to be unrelated to protein expression. Therefore, it is of great importance to determine if the observed genomic difference could impact its expressed protein outcome. Taoka et al. (2004) found that the majority of horizontally transferred genes in the genome of $E$. coli are not translated into proteins. Recent data from transcriptomic and/or proteomic profiling suggest that marker panels derived from transcriptomic or proteomic profiling are superior to single genes or markers, in differentiating non-infectious from sepsisassociated systemic inflammation, and thus may overcome some of the limitations of procalcitonin (Johnson et al., 2007; Tang et al., 2009). 
The use of biomarkers might help to avoid antibiotic misuse and overuse and to curb the rising incidence of microbial resistance. Increasing rates of bacterial resistance among common pathogens are threatening the effectiveness of even the most potent antibiotics. Through proteome analysis we showed how mechanisms of antimicrobial resistance can affect other important characteristics, like virulence, possibly resulting in low dissemination of such strains. Further work focusing on the interactions between antimicrobial resistance and virulence mechanisms is important. There is also a need for further epidemiological studies to determine whether different kinds of disinfectants contribute to the emergence of antibiotic resistance in order to establish the best practices to prevent or minimize the selection of antibiotic resistance (Karatzas et al., 2008).

\section{The potential role of proteomics in Salmonella research}

Functional genomics allows identification of complex pathways and interactions between gene expression products that provides insight into processes beyond their clinical appearance. Single cell signaling stimuli can define complex cellular pathways but multicellular and whole organism systems require an understanding of complex interrelationships, both structurally and temporally. These complex interrelationships are based on numerous individual components, diffuse interconnectivity between components, differences in spatio-temporal relations, and complexity in signaling network control interactions. Together, comparative proteomics, MS and bioinformatics contributed to the achievement of significant progress on the characterization of bacterial pathogens (Osman et al., 2009). MALDI has been used for the identification of bacteria since 1996 (Holland et al., 1996; Krishnamurthy \& Ross, 1996) and this technique can be used for determining the causes of infection in patients, for the detection of bioterrorism agents, for the detection of toxic molds and bacteria in indoor air and for the detection of infectious agents in water (Parker et al., 2010).

Nevertheless, a broader definition states that proteomics deals with the large-scale analysis of proteins, including identification, measure of expression levels and partial characterization by the analysis of pre-, CO-, and post-translational modifications, their structures, functions and interactions. Proteomics has four main objectives: (i) to identify all proteins from a proteome creating a catalogue of information; (ii) to analyze differential protein expression associated to a disease, different cell states, sample treatments and drug targets; (iii) to characterize proteins by discovering their function, cellular localization, PTMs, etc. and (iv) to describe and understand protein interaction networks (Palagi et al., 2006).

Proteomic profiling is a useful approach to obtain an overview of the proteins present in a bacterial system under differing conditions (DelVecchio et al., 2002; Lipton et al., 2002). Additionally, it can aid in understanding the molecular determinants involved with pathogenesis, which is essential for the development of effective strategies to combat infection and revealing new therapeutic targets (Lucas \& Lee, 2000). Therefore, proteomics presents one of the best ways to investigate changes in the genome expression profile (Leverrier et al., 2004). Protein profiles can reveal the complexity of expressed proteins in bacteria, representing phenotypic characteristics, but they can also provide an excellent approximation of a microorganism's genome information. Also, proteomic methodologies contribute to the determination of antimicrobial resistance mechanisms, through the capacity to analyze global 
changes of bacteria (Radhouani et al., 2010). The use of Salmonella reference protein maps may be helpful in the identification of proteins in different Salmonella strains. In addition, these maps can facilitate the determination of different growth conditions (Qi et al., 1996). Studying the proteome of Salmonella with its small genome (with an estimated coding potential of 4000 gene products) makes it theoretically simple to determine if a certain protein is known or novel. Further, the close evolutionary relationship between E. coli and Salmonella, in which protein homologues usually have similar sequences, allows a reliable assignment of proteins and PTMs which appears to be relatively rare. Also, the availability of decreased-virulencestrains, as a result of mutations in key regulatory proteins, allows the comparison of protein expression profiles between strains, which permits the identification of proteins under the control of a specific regulator (O'Connor et al., 1997).

Because Salmonella need to invade a specific host cell to initiate the disease process, the characterization of the Salmonella proteins that are induced during and following invasion of different types of mammalian cells is of particular interest (O'Connor et al., 1997), particularly in the development of new antimicrobial approaches. Studies performed by our research group have proven the capability of proteomics to provide results that allow the comparison between Salmonella strains, as long as the detection of proteins related to antibiotic resistance, pathogenesis and virulence in this species (Pinto et al., 2010). Therefore, our group developed an integrated genomic and proteomic evaluation of antibiotic resistance in Salmonella strains with different serotypes and antibiotic resistance phenotypes, recovered from faecal samples of wild rabbits and wild boars from the North of Portugal. All strains used in the referred study are listed in Table 1, which shows the resistance profiles of the different samples of Salmonella serotypes displayed in the 1-D gel. Analysis of different strains by SDS-PAGE gave reproducible whole-cell protein patterns which allowed differentiation among the serovars included in this study (Figure 4). The genetic characterization of antimicrobial resistance genes as well as their location and diversity is important in identifying factors involved in resistance, understanding the diversity of multidrug resistant strains, identifying genetic linkages among markers, understanding potential transfer mechanisms, and developing efficient detection methods.

Cell wall changes that result in reduced permeability can also be responsible for resistance to biocides and antibiotics. These common mechanisms of resistance to biocides and antibiotics should be a public health concern, and prevention of the dissemination of antibiotic-resistant strains in the environment and animal hosts, including farm animals and humans, is important (Karatzas et al., 2008). The application of proteomics to the antibiotic-discovery process, technically spoken, requires the same methodological approaches as those applied to study the physiological response to environmental stresses. Nevertheless, there are many potential questions to be asked that are specific for drug-discovery applications. Antibiotics exert their antibacterial activity via binding to and inhibition of certain molecular targets, thereby usually blocking a function essential for microbial survival. Therefore, one application of proteomics in drug discovery is the identification of novel antibacterial targets. Target identification will critically rely either on the availability of similar protein expression profiles for comparison or on the detailed investigation of proteome signatures induced by the compound tested. For target validation, proteome analysis of mutants may be helpful if an inhibitor of a novel target of interest is not yet available. For certain groups of inhibitors it might be beneficial to extend the analysis to different $\mathrm{pI}$ ranges or to include different protein fractions to increase the 
number of marker proteins. For instance, it would be interesting to identify marker proteins in the membrane fraction that help differentiate between membrane-active antibacterial compounds (Apfel et al., 2001; Bandow et al., 2003; Evers et al., 2001; Gmuender et al., 2001; Gray \& Keck, 1999; Singh et al., 2001).

\begin{tabular}{lll}
\hline \multicolumn{1}{c}{ Sample } & \multicolumn{1}{c}{ Serotype } & \multicolumn{1}{c}{ Resistance profile } \\
\hline J27(1) & S. Typhimurium & AMP; TET; STR; CHL \\
J32(2) & S. Typhimurium & AMP; TET; STR; CHL \\
C71(1) & S. Typhimurium & AMP; TET; STR; CHL \\
P40(a) & S. Typhimurium & AMP; TET; STR; CHL \\
P16(1) & S. Typhimurium & AMP; TET; STR; CHL \\
P20(2) & S. Enteritidis & AMP; TET; STR; NAL; CHL \\
P29(2) & S. Rissen & AMP; TET; STR; NAL; SXT \\
J45(1) & S. Rissen & AMP; TET; SXT \\
P1(1) & S. Enteritidis & AMP; TET; NAL; SXT \\
AVT14(1) & ND & TET; SXT \\
C12(1) & S. Rissen & AMC; AMP; TET; STR; SXT \\
C16(1) & S. Typhimurium & AMP; TET; AK; STR; CHL \\
C40(2) & S. Typhimurium & AMP; STR; CHL \\
P57(c) & S. Enteritidis & TOB; STR \\
C37(1) & S. Enteritidis & - \\
J15(2) & S. Typhimurium & AMP; STR; CHL \\
\hline
\end{tabular}

J-wild boars; C-wild rabbit; $\mathrm{P}$ - swine; AVT - ostrich; AK - amikacin; AMC - amoxicillin-clavulanic acid; AMP - ampicillin; CHL - chloramphenicol; NAL - nalidixic acid; STR - streptomycin; SXT — sulfamethoxazole-trimethoprim; TET - tetracycline; TOB - tobramycin; ND - not determined. Adapted from Journal of Proteomics, 73 (8), (Pinto et al., 2010), Genomic and proteomic evaluation of antibiotic resistance in Salmonella strains, 1535-1541, Copyright (2010), with permission from Elsevier.

Table 1. Resistance profiles of the different samples of Salmonella serotypes displayed in the 1-D gel.

According to these patterns, two different serotypes were chosen based on differences in serotypification and antibiotic resistance to proceed to a full proteomic study: the wild boar S. Typhimurium J15(2) strain, which demonstrated resistance to three antimicrobial agents (ampicillin, streptomycin and chloramphenicol) and S. Enteritidis C37(1), recovered from a wild rabbit, where no antibiotic resistance was found. 2-DE (Figure 5) combined with MS (MALDI-TOF/TOF) and then the correlation with web databases allowed the exact identification and characterization of proteins related to antibiotic resistance, pathogenesis and virulence in both Salmonella strains (Table 2). In S. Enteritidis isolated from a wild rabbit [C37(1)], the protein "Virulence transcriptional regulatory protein phoP" was detected in spot 47 and was previously reported in three different Salmonella strains: S. Typhi (accession number Q8Z7H2), S. Typhimurium (P14146) and S. Choleraesuis (Q57QC3). Protein phoP is a member of the two-component regulatory system phoQ/phoP that regulates the gene expression involved in virulence and resistance to host defensive antimicrobial peptides, promoting intramacrophage survival of $S$. Typhimurium (Miller et al., 1989). Transcriptional regulatory protein basR/pmrA (P36556) was also found in C37(1), and is related to $S$. Typhimurium where it is involved with processes of antibiotic resistance and pathogenesis, more exactly in the resistance to polymyxin (McClelland et al., 2001). 


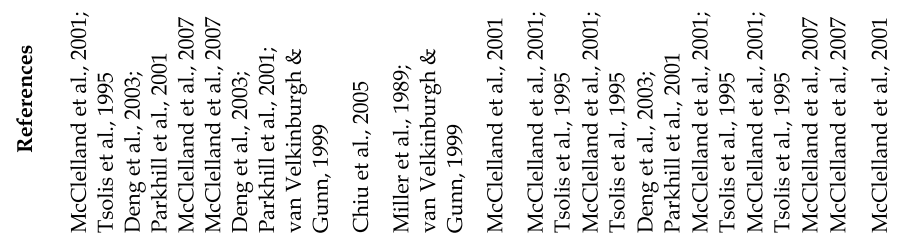

密密过 \& \& \& \& \& \& \& \& \& \& \& \& \& \&

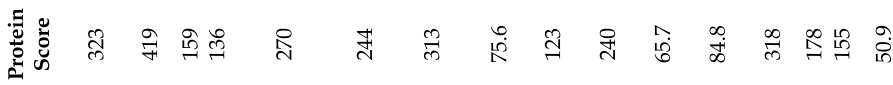

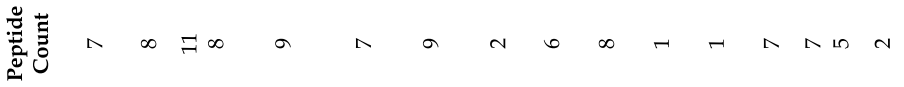

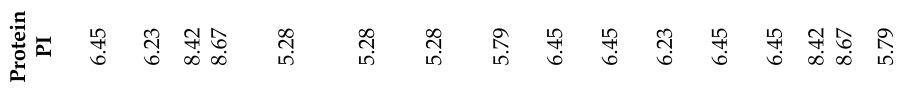

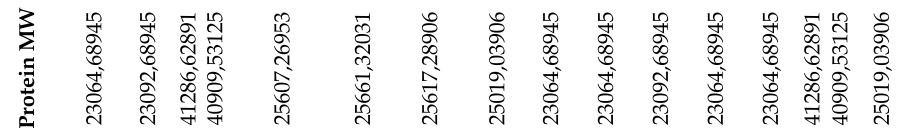

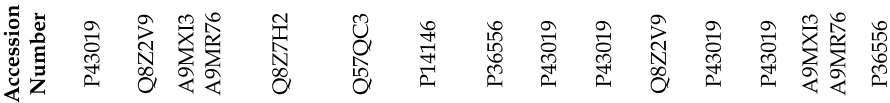

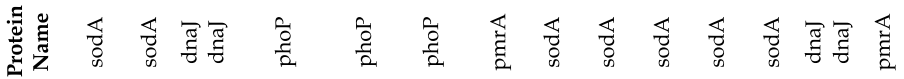

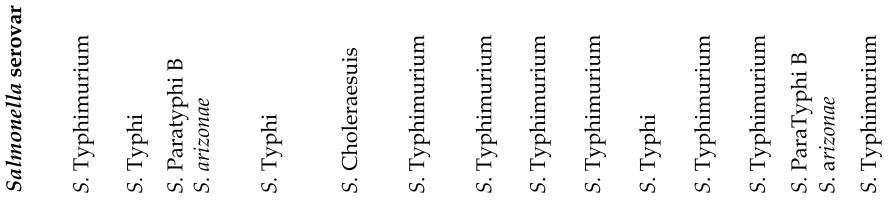

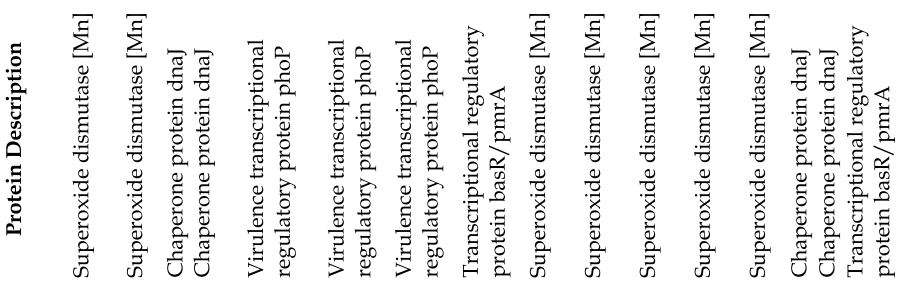

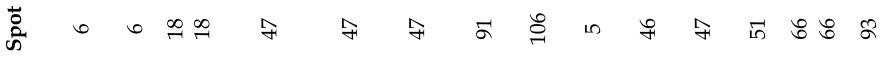

施

Adapted from Journal of Proteomics, 73 (8), (Pinto et al., 2010), Genomic and proteomic evaluation of antibiotic resistance in Salmonella strains, 1535-1541, Copyright (2010), with permission from Elsevier.

Table 2. Protein spots identification and sequencing results from Salmonella spp. isolates C37(1) and J15(2) 2-DE gels, by MALDI-TOF. 


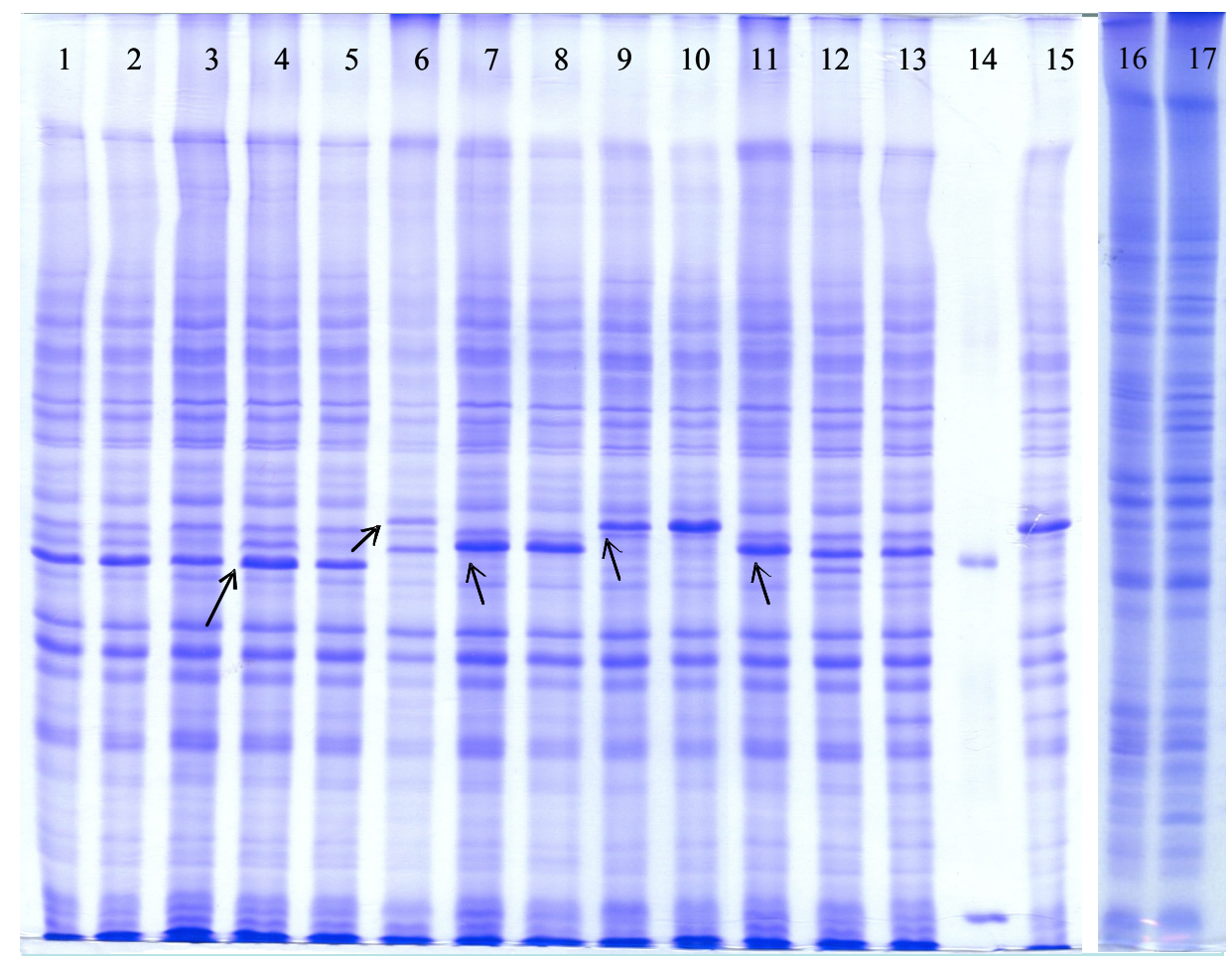

Fig. 4. SDS-PAGE of total protein extracts from Salmonella serotypes. 1-J27(1); 2-J32(2); 3C71(1); 4-P40(a); 5-P16(1); 6-P20(2); 7-P29(2); 8-J45(1); 9-P1(1); 10-AVT14(1); 11-C12(1); $12-$ C16(1); 13-C40(2); 14- Marker; 15-P57(c); 16-C37(1); 17-J15(2). Arrows indicate the clearest differences between protein samples. Reprinted from Journal of Proteomics, 73 (8), (Pinto et al., 2010), Genomic and proteomic evaluation of antibiotic resistance in Salmonella strains, 1535-1541, Copyright (2010), with permission from Elsevier.

Since horizontal gene transfer among bacteria is a common mechanism of antibiotic resistance transmission within different bacteria, the presence of this protein in Salmonella carried in a faecal sample of a wild animal represents a concern, in the event of contact with domestic or commercial animals, or even humans. In $S$. Typhimurium J15(2), recovered from the faecal sample of a wild boar, the transcriptional regulatory protein basR/pmrA (P36556) was also found. Protein Superoxide dismutase [Mn] (sodA) was found in both isolates and is known to be responsible for the destruction of radicals that are normally produced within the cells and that are toxic to biological systems. The presence of this protein allows these bacteria to prevent an early killing by J774 cells and thus play a minor role in Salmonella pathogenesis (Tsolis et al., 1995). Chaperone protein dnaJ was also identified and is important for its relationship with the stress response mechanism towards heat, a very important reaction for the survival of bacteria such as Salmonella and its contribution to antibiotic resistance capability. This work, albeit preliminary in nature, reveals the complexity of expressed proteins in bacteria or different serotypes and profiles of antibiotic resistance. Bearing in mind that serotypes are related to infectious processes in 
humans and animals, it is important to explore the proteome of new strains which might serve as protein biomarkers for biological activity.
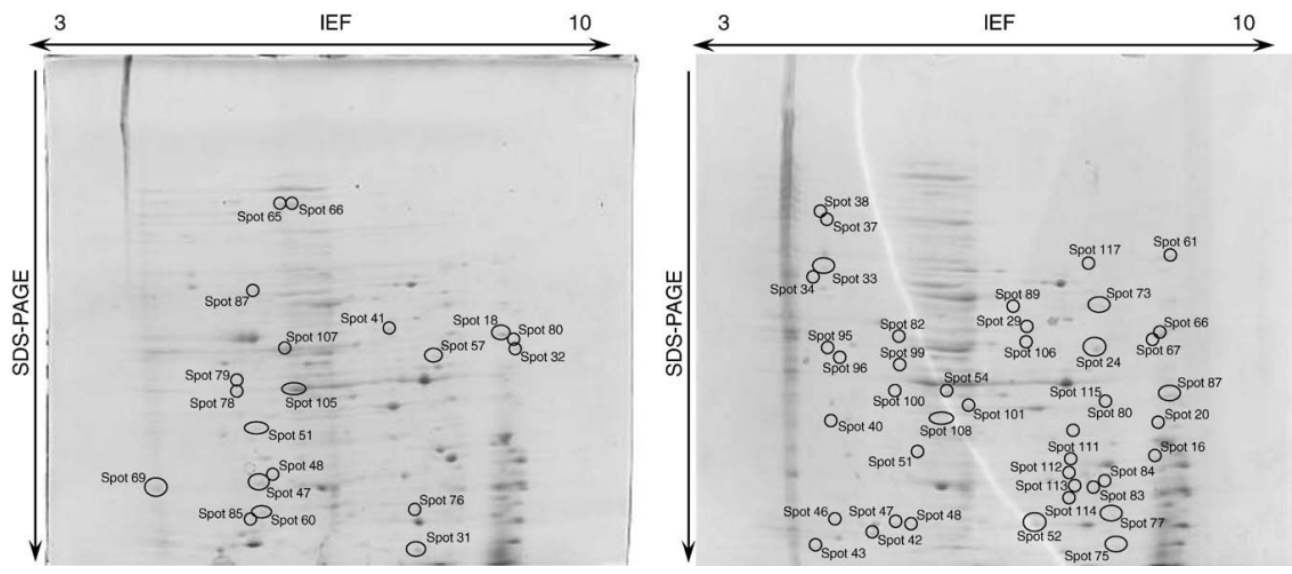

Fig. 5. 2-DE gel image of Salmonella samples with IPG strips pH3-10. Left: Serotype C37(1); Right: Serotype J15(2). Reprinted from Journal of Proteomics, 73 (8), (Pinto et al., 2010), Genomic and proteomic evaluation of antibiotic resistance in Salmonella strains, 1535-1541, Copyright (2010), with permission from Elsevier.

\subsection{Proteomic mapping analysis and proteomic signatures}

Proteomics already allowed substantial progress in elucidating the basic regulatory networks that form the basis for the extraordinary capacity of bacteria to adapt to a diversity of lifestyles and external stress factors. The application of this method for antibacterial drug-discovery purposes, however, is still in its early days. One reason for this phenomenon is the fact that the discovery of novel targets, which is one of the most important applications of proteome studies in other areas of drug discovery, is not so much a bottleneck in antibiotic research, because the pathophysiology of most bacterial infections is relatively well-understood and simple: killing the bacterium or interfering with its growth and, possibly, its virulence is usually all it takes. The term "proteomic signature" is defined by a subset of proteins, whose expression levels are characteristic for a defined condition (VanBogelen et al., 1999). To spot a proteomic signature, it is essential to recognize the connection between the expression levels of specific proteins and a particular physiological state. The establishment of protein signatures can be extremely helpful in the interpretation of a protein expression profile obtained under an unprecedented growth condition (Brotz-Oesterhelt et al., 2005).

Since its inception, the goal of proteomics has been the complete characterization of all proteins. However, considering the proteome of an organism as all protein forms expressed, including splice isoforms and PTMs, this goal consists of a considerably complex amount of information that needs to be gathered. Whereas the genome of an organism generally does 
not vary from cell to cell, the proteome will change in response to different stimuli, even for a single cell (Han et al., 2008). When grown under moderate stress conditions, bacteria may develop an adaptive response, allowing them to cope with subsequent more severe stresses. In general, this adaptation phenomenon appears to involve multiple genes encoding stress proteins, which can be specifically induced by a particular stress factor or induced by several conditions (Rince et al., 2002).

Protein maps associate a protein spot from a 2D gel to its corresponding ORF and also provide the respective knowledge pertaining to protein function (Brotz-Oesterhelt et al., 2005). 2D-PAGE, as already referred, is the most used technique for protein mapping and analysis. However, there are by now published studies proving the potential of non-gelbased technologies, like liquid chromatography coupled with ion-trap tandem MS. The number of proteins identified in both techniques may be quite similar, but it is possible to detect some different types of proteins (Brotz-Oesterhelt et al., 2005). Analyzing the proteome of a human pathogen like Salmonella has proven to be crucial. The establishment of protein reference maps is a significant point for many physiological studies that may follow. Nevertheless, protein maps only represent virtual compilations of all proteins ever detected or identified in an organism; they do not disclose which subset of proteins is expressed under specific growth conditions. In order to obtain such information, proteinexpression profiles must be generated (Brotz-Oesterhelt et al., 2005).

The adaptation status of each organism to a specific ecological niche is reflected by the different types of proteins encoded and variations in their amino acid sequences. That adaption is achieved by differences in post-transcriptional and post-translational regulation that mediate the adaptation on the protein level. Thus, proteins that constitute a proteomic signature for a specific condition in one organism do not necessarily belong to the proteomic signature for the same physiological state in another organism.

Genomic and proteomic technologies have revolutionized the way we design and conduct current biological experiments. Our ability to rapidly analyze hundreds of expressed proteins and identify which gene encodes a specific protein generates a vast amount of information essential in examining different but interrelated pathways within the organism. Knowing which proteins are phosphorylated, for instance, may explain the differential expression of certain genes responsible for attenuating virulence or conferring host specificity. Beyond these, results of proteomics studies may be used in the development of a more potent vaccine, rapid detection methodology and fingerprinting, and novel antimicrobial drugs (DelVecchio et al., 2002; Lipton et al., 2002). Proteomic technologies have been greatly refined during the past decade and have been applied to investigate differences in the protein expression profiles of cells grown under a broad spectrum of growth conditions and with different stress factors including some antibiotics inhibiting protein synthesis or gyrase function.

\subsection{Comparative proteomics and antibacterial drug discovery process}

Evaluation of protein profiles in response to multiple stress mechanisms, such as sensitivity to antibiotics or modifications related to antibiotic resistance, could represent a valid and integrating approach for the development of new therapeutic strategies (Roncada et al., 
2009). It is widely recognized that the development of novel antibacterial agents without cross-resistance to existing antibiotics should have high priority on any meaningful public health agenda. Therefore, it is not surprising that proteome analysis of the consequences of antimicrobial treatment for bacteria has recently gained increasing interest. This approach provides a deeper insight into bacterial response to a certain antimicrobial treatment and benefits are expected in many other aspects of modern drug development such as the identification of novel target areas and the elucidation of the molecular mechanisms of action of novel drug candidates.

Antibiotics exert their antibacterial activity by binding to and inhibiting certain molecular targets, thereby usually blocking a function essential for microbial survival. Thus, one application of proteomics in drug discovery is the identification of novel antibacterial targets. Some available studies in which proteomics was performed with clear emphasis on antibacterial drug discovery focus on either target validation or mode of action, including those that aim at a better molecular understanding of the mechanisms of action of existing drugs (Apfel et al., 2001; Bandow et al., 2003; Evers et al., 2001; Gmuender et al., 2001; Gray \& Keck, 1999; Singh et al., 2001). In these studies, the proteome of bacteria grown in vitro under standardized conditions in the presence and absence of the antibiotic of interest is analyzed with respect to changes in the protein-expression pattern.

Thus, significant progress has been made on the characterization of bacterial pathogens through comparative proteomics correlated with MS and bioinformatics (Pinto et al., 2010). In comparative proteomic studies, proteins from different biological states are quantitatively compared to obtain a complete understanding of the biological processes affecting their expression and/or in which they are involved (Renzone et al., 2005). This is a two-step process in which proteins within cellular extracts are first fractionated to reduce sample complexity, and then the proteins are identified by MS (Minden, 2007). Two-dimensional electrophoresis is the long-time standard for protein separation as it provides a direct method to visualize changes in proteins between complex proteome samples and is able to resolve thousands of proteins; however, it has suffered from poor reproducibility and limited sensitivity (Minden, 2007; Veenstra, 2007). DIGE was developed to overcome the reproducibility and sensitivity limitations and provides a reliable and sensitive platform to discover proteome changes in a boundless variety of circumstances (Minden, 2007). Discovery proteomics also involves multi-dimensional separation steps and liquid chromatography-tandem mass spectrometry (LC-MS/MS) with long gradients (Qi et al., 1996).

According to Brotz-Oesterhelt et al. (2005) successful exploitation of those technologies for the antibacterial drug discovery process depends on further progress in three main areas: i) data collection, which should be expanded to comprise as many antibacterial compounds with diverse mechanisms of action as possible, to ideally cover all relevant targets (for novel targets, where such reference antibiotics are not always available, the analysis of conditional mutants should be included); ii) the data analysis tools, which should be optimized or developed to efficiently handle the enormous datasets and to facilitate data evaluation in terms of mechanism-specific signatures (by including clustering, chemometric, and artificial intelligence approaches, for example); and iii) 
further methodological progress in order to increase the speed, throughput, and reproducibility of $2 \mathrm{D}$ gel-based as well as non-gel-based techniques. In comparative proteomics, data analysis in most cases concentrates on listing the proteins with significantly altered expression levels, which are subsequently discussed with respect to the current knowledge of the antibiotic's mode of action. It is known that antibiotics such as $\beta$-lactams, glycopeptides, D-cycloserine and fosfomycin, act at different stages of bacterial cell wall synthesis and that compounds such as quinolones inhibit DNA gyrase. For all proteins with an altered expression in response to a particular stimulus, the term "stimulon" was coined (Neidhardt et al., 1990) to describe the changes in protein expression on a phenotypic level. Therefore, if antibiotics with known activity in a certain metabolic pathway are investigated, the data can be exploited to define a pathwayspecific stimulon or a proteomic signature that is indicative of the inhibition of a specific target, which might prove to be useful later in identifying and characterizing novel antibiotics that act within that pathway. Another application for proteomic studies within the drug-discovery process is the verification that a compound, which inhibits the activity of a desired isolated protein in a biochemical target assay, acts indeed as expected when tested against whole bacterial cells, and does not kill the cell due to other, not targetrelated, possibly undesired and non-specific activities such as general membrane perturbation or intercalation into nucleic acids.

Gene-expression analysis is increasingly important in many fields of biological research. Understanding patterns of expressed genes is expected to provide insight into complex regulatory networks and will most probably lead to the identification of genes relevant to new biological processes, or implicated in disease. Real-time PCR provides the simultaneous measurement of gene expression in many different samples for a limited number of genes, and is especially suitable when only a small number of cells are available (Fink et al., 1998). Many changes in the protein synthesis patterns in response to the antibiotics were consistent with existing knowledge on the modes of action and on the cellular responses to changes in environmental conditions. Inhibition of Ile-tRNA synthetase induced the stringent response, and protein synthesis inhibitors that interfere with translation accuracy induced class I heat shock proteins known to be induced by misfolded proteins. Each response, however, also yielded new information, for example, the expression of proteins with unknown function, a shift in the pIs of proteins newly synthesized after actinonin treatment, or the good correlation of the protein expression profiles of nitrofurantoin and diamide (Bandow et al., 2003). The NCBI-matched proteins that show overregulation were then further confirmed on the mRNA level by quantitative real time PCR. Identified proteins were representing diverse functional activities including energy production, metabolism, and nucleic acid synthesis. Interestingly, some recognized proteins have some relevance to bacterial virulence e.g. Salmonella pathogenicity island 1 effector protein, T-cell inhibitor protein, response regulator protein, paratose synthetase protein (RfbS) and heat shock protein 90. Comparative proteomics analysis of the cytosolic proteins of $S$. Gallinarum and $S$. Enteritidis isolated from poultry was performed and revealed the presence of some proteins of unknown function, which raise the speculation for their importance in either host adaptation or pathogenicity among S. Gallinarum serovars (Osman et al., 2009). 
Current strategies for the discovery of novel antibacterial agents can be categorized as being either directed against a specific molecular target or based on reverse genomics. In the target-based approach, a certain molecular target is carefully selected and then compound libraries are screened specifically for inhibitors of its function. In the "reverse-genomics" approach, a compound is selected for its promising antibacterial activity and the target is determined in a second step.

In antibiotic drug discovery two major strategies are used (Bandow et al., 2003): the evaluation of structural variations among existing antibiotic classes in order to find compounds which hit the same targets by similar molecular mechanisms and the evaluation of novel antibiotic substances arising either from high-throughput target-based assays, or from antibacterial activity screening. If, through its antibacterial activity alone, a novel compound class arouses interest, its molecular target needs to be identified so that undesirable side effects on eukaryotic cells can be minimized (target identification). In addition, for structurally modified antibiotics or compounds derived from the target-based assays it is necessary to prove that interaction with the cellular target is indeed the direct cause for bacterial cell death (target validation).

Bandow et al. (2003) used a proteomic approach to study the responses of bacteria to antibacterial compounds and demonstrated that proteome analysis is useful for both target identification and target validation. They began building a database from 2D protein analysis of bacterial responses to antibiotic treatment, considering all important established and emerging antibiotic classes as well as some substances causing generalized cell damage. Bacillus subtilis was the chosen organism because its genome is fully sequenced and earlier proteome studies focusing on the description of protein signatures of environmental stimuli were accessible in the Sub2D database. Therefore, 30 antimicrobial compounds were studied, most of which have been well characterized in terms of their mechanisms of action and by comparison with known antibiotics, and they were able to predict the mode of action of the structurally new antibacterial BAY 50-2369. This study also provided a better understanding of nitrofurantoin's mode of action, which has been used for decades in the treatment of urinary tract infections. Hence, Bandow et al. (2003) showed that, by mirroring the complex molecular reactions of bacteria, proteomics is able to enlarge the view of known antibiotics and assist in the discovery of new drugs.

\section{Effects of external stress on the Salmonella proteome}

The capability of growing many bacterial species in well-defined artificial culture media has been a pre-requisite for the current in-depth understanding of bacterial physiology. Repeatedly, those culture media provide the most advantageous growth conditions that allow maximal and uniform logarithmic bacterial growth until some components of the medium become exhausted and logarithmic growth ceases. Under such optimal conditions, the protein composition of the cell is usually quite constant and tuned to support the special conditions of rapid growth. However, on the external environment, outside the laboratory, bacteria face much less supportive and highly variable growth conditions, with respect to temperature, $\mathrm{pH}$, osmolarity, nutrient availability, host interactions, etc. Those stress situations do not principally differ from the stresses induced by antibiotic attack. Antibiotics are frequently encountered by many bacteria in their natural habitats, because many 
microorganisms produce them to suppress the growth of competitors. Hence, even antibiotic classes that stem from purely synthetic approaches and are never encountered by bacteria during evolution can, to a certain extent, mimic "natural" processes for which bacteria have developed regulatory mechanisms (Brotz-Oesterhelt et al., 2005).

It is critical for survival that the protein composition of a cell is constantly adjusted to meet the challenges of changing environmental conditions. Thus, bacteria respond to their environment with programmed changes in gene expression and their evolutionary success is strongly dependent on their ability to respond to external adverse conditions through a set of behavioural responses (Brotz-Oesterhelt et al., 2005). Proteomic technologies appear to be the natural tools to study the consequences of these regulatory processes on protein composition since a large number of external and internal signal molecules and signal transduction processes are present in bacteria to adapt their protein composition to the changing requirements of their environment (Armitage et al., 2003). During the past decade, proteomic technologies have been greatly refined and have been applied to investigate differences in the protein expression profiles of cells grown under a broad spectrum of growth conditions and with different stress factors, including some antibiotics (Bandow et al., 2003).

The number of detected proteins in response to stress mechanisms represents only a small proportion of the predicted proteome, as many genes may only be induced and expressed under certain conditions. Coldham et al. (2006) evaluated the effect of fluoroquinolone exposure on the proteome of S. enterica serovar Typhimurium using strain SL1344 and a MAR mutant. Broth cultures of strain SL1344 were treated with ciprofloxacin and enrofloxacin. Then, protein expression was determined by two-dimensional HPLC-MS $n$ and also, after exposure to ciprofloxacin, by two-dimensional gel electrophoresis (Figure 6).
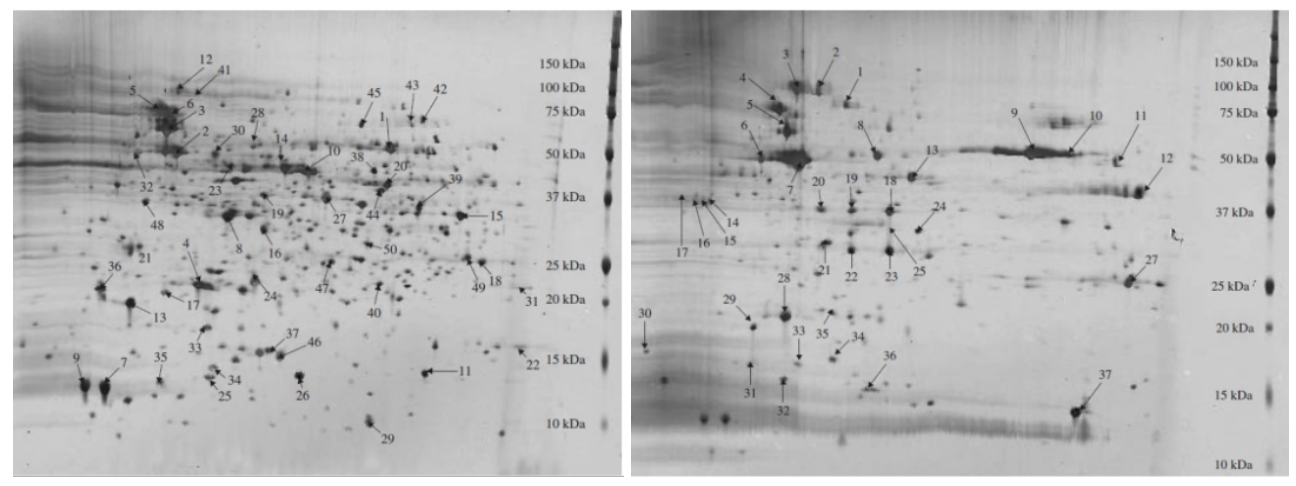

Fig. 6. Silver-stained second-dimension electrophoretogram of the proteome of $S$. Typhimurium extracted from untreated cultures (left) and from a culture following treatment with ciprofloxacin (right). Coldham et al., 2006, Effect of fluoroquinolone exposure on the proteome of $S$. Enterica serovar Typhimurium. Journal of Antimicrobial Chemotherapy, 2006, 58 (6): 1145-1153, by permission of Oxford University Press. 
Coordinated regulation of protein effector expression is a key feature of innate reduced susceptibility to multiple antibiotics (Randall \& Woodward, 2002). The chromosomal MAR locus of E. coli, in cooperation with other regulatory loci, plays a pivotal role in innate reduced susceptibility (circa 4-fold) to some unrelated antibiotics and certain disinfectants (Levy, 2002). Overexpression of the AcrAB-TolC efflux pump contributes to multiple antibiotic resistance in $E$ coli, and has also been associated in conjunction with mutations in gyrA with resistance to fluoroquinolones in S. enterica. The AcrAB efflux pump of E. coli and S. enterica belongs to the resistance/nodulation/cell division (RND) family and consists of a proton antiporter (AcrB) and a membrane fusion protein (AcrA) (Borges-Walmsley \& Walmsley, 2001; Zgurskaya \& Nikaido, 2000). These two proteins associate with an outer membrane channel protein, such as TolC, to form a functional efflux pump unit providing selective molecular translocation of solutes from the periplasm to the external environment. Reduced expression of porin proteins located in the outer cell membrane may act synergistically with efflux pumps to reduce penetration of antibiotic into the bacterial periplasm. Whilst much is understood about the mechanisms of efflux, little is known of the secondary responses enabling the physiological adaptation of Salmonella to fluoroquinolones. This study demonstrated an increased and decreased expression of a wide range of proteins on the proteome of $S$. enterica serovar Typhimurium after fluoroquinolone exposure; the basal expression of the efflux system AcrAB/TolC, which contributes to antibiotic resistance, was elevated in the multiple antibiotic resistant mutant when compared with the untreated wild-type and also increased following treatment with ciprofloxacin. Therefore, an amplified expression of AcrAB/TolC was associated with resistance while other increases, such as in $\mathrm{F}_{1} \mathrm{~F}_{0}$-ATP synthase and Imp, were a response to fluoroquinolone exposure (Coldham et al., 2006).

Proteomic analysis of triclosan resistance in S. enterica serovar Typhimurium by proteomics identified a set of proteins with commonly altered expression in all triclosanresistant mutants. According to the authors, this 'triclosan resistance network' included nine proteins involved in the production of pyruvate or fatty acid. This may represent a mechanism by which the triclosan-resistant mutants have increased throughput of fatty acid biosynthesis by increased pyruvate production or have altered metabolic pathways in order to produce fatty acid via a different pathway (conversion of glycerol to hexadecanoate or increased citrate production to feed acetyl-CoA production). Proteomic data revealed specific patterns of protein expression in each mutant as well as the 25 proteins that constitute a common metabolic resistance network in all mutants studied. These data show that triclosan resistance is multifactorial and a number of resistance mechanisms act in synergy to achieve high-level resistance. This indicates that triclosan is likely to act on multiple targets within the cell rather than being exclusively an inhibitor of fabI (Webber et al., 2008). The physiological status of supercritical carbon dioxide (SC$\mathrm{CO}_{2}$ ) treated $S$. enterica serotype Typhimurium was analyzed by using gas chromatography mass spectrometry (GC-MS) analysis of fatty acids with principal component analysis and two-dimensional electrophoresis for protein profiling. From the results of these systemic analyses, it was revealed that $\mathrm{SC}-\mathrm{CO}_{2}$ caused significant alterations to the profiles of fatty acids and proteins of the cells (Kim et al., 2009). This data and other results of stress induced/repressed proteins obtained by proteomics in Salmonella spp. are summarized in Table 3. 


\begin{tabular}{|c|c|c|c|c|}
\hline Stress & $\begin{array}{l}\text { Differential } \\
\text { expression }\end{array}$ & $\begin{array}{l}\text { Identified } \\
\text { Proteins }\end{array}$ & $\begin{array}{l}\text { Relevant Protein } \\
\text { Function }\end{array}$ & Reference \\
\hline Acid & Overexpression & fliC & $\begin{array}{l}\text { Virulence during } \\
\text { infection }\end{array}$ & $\begin{array}{l}\text { Jindal } \\
\text { et al., } 2011\end{array}$ \\
\hline \multirow[b]{2}{*}{ Anaerobiosis } & Overexpression & $\begin{array}{l}38 \text { proteins, more } \\
\text { importantly Mdh, } \\
\text { PflI, FrdA, AckA, } \\
\text { AdhE }\end{array}$ & $\begin{array}{l}\text { Metabolism (mixed- } \\
\text { acid fermentation) }\end{array}$ & \multirow[b]{2}{*}{$\begin{array}{l}\text { Encheva } \\
\text { et al., } 2009\end{array}$} \\
\hline & Underexpression & $\begin{array}{l}42 \text { proteins, more } \\
\text { importantly ArgT, } \\
\text { HisJ, GlnQ, GltI, } \\
\text { OppA, DppA, } \\
\text { SodA, SuhB, DnaK, } \\
\text { GroS, SspA, PspA, } \\
\text { OsmC, UspG }\end{array}$ & $\begin{array}{l}\text { Transport, stress- } \\
\text { response and } \\
\text { chaperone function }\end{array}$ & \\
\hline Fluoroquinolone & Overexpression & $\begin{array}{l}43 \text { proteins, more } \\
\text { importantly AtpA, } \\
\text { AtpC, AtpD, } \\
\text { AtpH, Imp, TolC, } \\
\text { AcrB }\end{array}$ & $\begin{array}{l}\text { Mechanisms of } \\
\text { resistance }\end{array}$ & $\begin{array}{l}\text { Coldham } \\
\text { et al., } 2006\end{array}$ \\
\hline $\begin{array}{c}\text { Hydrogen } \\
\text { Peroxide }\left(\mathrm{H}_{2} \mathrm{O}_{2}\right)\end{array}$ & $\begin{array}{c}\text { Over-and } \\
\text { underexpression }\end{array}$ & $\begin{array}{l}76 \text { proteins, more } \\
\text { importantly SipC, } \\
\text { SopB, SipA }\end{array}$ & $\begin{array}{l}\text { Survival and } \\
\text { replication under } \\
\text { oxidative stress and } \\
\text { during infection }\end{array}$ & $\begin{array}{l}\text { Kim et al., } \\
2010\end{array}$ \\
\hline Propionate (PA) & Overexpression & $\begin{array}{l}\text { Dps, CpxR, RplE, } \\
\text { RplF, SodA }\end{array}$ & $\begin{array}{l}\text { PA-induced acid } \\
\text { resistance, virulence } \\
\text { and pathogenesis }\end{array}$ & $\begin{array}{l}\text { Calhoun } \\
\text { et al., } 2010\end{array}$ \\
\hline Thymol & $\begin{array}{c}\text { Over- and } \\
\text { underexpression }\end{array}$ & $\begin{array}{l}45 \text { proteins, more } \\
\text { importantly Trx1, } \\
\text { FtsZ, CheW, } \\
\text { GroEL, DnaK }\end{array}$ & $\begin{array}{l}\text { Antioxidant and } \\
\text { chaperon function }\end{array}$ & $\begin{array}{l}\text { Di Pasqua } \\
\text { et al., } 2010\end{array}$ \\
\hline Triclosan & Overexpression & $\begin{array}{l}25 \text { proteins, more } \\
\text { importantly ArcA, } \\
\text { GcvP, MdH, MaeB, } \\
\text { GapA, PpS, FadB, } \\
\text { GltA, GlpK }\end{array}$ & $\begin{array}{l}\text { Pyruvate or fatty acid } \\
\text { production } \\
\text { (Metabolic triclosan } \\
\text { resistance network) }\end{array}$ & $\begin{array}{l}\text { Webber } \\
\text { et al., } 2008\end{array}$ \\
\hline
\end{tabular}

Table 3. Summary of some results on stress induced/repressed proteins obtained by proteomics in Salmonella spp.

\section{Remarks on proteomics as a biomarker search tool}

After its steep rise in the late 1970s and the early 1980s after O'Farrell's outstanding publication, there was a slow decline of the application of 2-DE in the late 1980s due to the 
inability to identify the gel-separated proteins of interest on a large scale. However, after the introduction of large-scale genome sequencing, the development of MS methods for the analysis of proteins and peptides, progress in bioinformatic tools and the rise of proteomics in general has experienced a revival and is today by far the most commonly applied protein separation technology in proteome research (Görg et al., 2009). Recent advances in biological and analytical sciences have led to an unprecedented interest in the discovery and quantification of endogenous molecules which serve as indicators of drug safety, mechanism of action, efficacy, and disease state progression. By allowing better decisionmaking, these indicators, referred to as biomarkers, can dramatically improve the efficiency of drug discovery and development (Ackermann et al., 2006).

Comparative genomics and several genomic tools have been used to identify virulence factors and genes involved in environmental persistence of pathogens. Proteomics has been contributing to a wide-range of scientific disciplines, but perhaps no area is more critical than the discovery of novel biomarkers. The extraordinary developments made in proteomic technologies in the past decade have enabled investigators to search for biomarkers by scanning complex proteome samples using unbiased methods (Veenstra, 2007). Currently, the search for protein biomarkers has been dominated by the employment of MS. Its high mass accuracy, resolution, dynamic range, sensitivity and even more importantly the speed at which MS/MS is performed, allowing thousands of proteins to be unambiguously identified, have made MS an invaluable tool for biomarker discovery (Blonder et al., 2011).

To identify novel diagnostic and therapeutic biomarkers, investigators focus on the discovery of proteins that are more or less abundant in samples obtained from patients with a specific disease compared to those acquired from healthy-matched control patients. There are a number of different MS-based methods to conduct these studies such as 2-DE/MS, proteomic profiling, stable-isotope proteome tagging and subtractive proteomics (for detailed description of each method see Veenstra, 2007).

Recent data suggests that marker panels derived from transcriptomic or proteomic profiling are superior to single genes or markers in differentiating non-infectious from sepsisassociated systemic inflammation (Johnson et al., 2007). Early and adequate antibiotic therapy is mandatory for successful sepsis therapy; hence a rapid diagnosis of infection and sepsis is of great significance. Diagnostic uncertainty is usually compensated by the liberal use of broad-spectrum antibiotics which leads to increased drug resistance. Therefore, the use of these biomarkers might help to avoid antibiotic misuse and overuse and to curb the rising incidence of microbial resistance (Reinhart \& Hartog, 2010).

With the advent of large-scale proteomic sequencing, the general belief was that biomarkers would be obvious within the data sets but unfortunately the results showed numerous background proteins that are routinely identified but have little value as biomarkers and numerous proteins that show a difference in comparative studies but their value as a reliable biomarker is extremely difficult to determine (Blonder et al., 2011). Having too many potential biomarkers is considered a problem when examining the workflow required to validate a biomarker for clinical use (Figure 7). In this scheme, thousands of analytes are measured in a few samples and when potential biomarkers are found, a more direct approach is taken to specifically measure these potential biomarkers again in a small 
number of samples to qualify the results from the discovery stage. The analytes that pass the qualification stage are then specifically measured in a larger number of samples to verify their utility as biomarkers. Those that pass the verification stage are then measured in a very large number of clinical samples to provide final validation that these proteins can function reliably (Blonder et al., 2011).

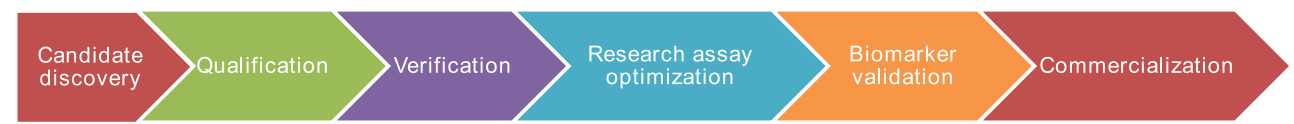

Fig. 7. The six essential process components in the biomarker pipeline: candidate discovery, qualification, verification, research assay optimization, biomarker validation and commercialization. Based on Rifai et al., 2006: Protein biomarker discovery and validation: The long and uncertain path to clinical utility. Nat Biotechnol, 24(8): 971-983.

The advances made in proteomic technology, primarily in the field of MS, allowed to scrutinize proteome samples to a far greater extent than previously possible. There are many options available to measure the relative abundance of proteins but unfortunately the number of biomarkers that have ultimately been successfully validated using these discovery approaches is discouraging - between 2003 and 2008, only 7 protein biomarkers were approved by the US FDA (Qi et al., 1996). In fact, MS-based studies are able to come up with very large numbers of "potential" biomarkers but the challenge relies on how to identify those that have the highest chance of being validated in a well-controlled clinical trial. Validation of a single biomarker is expensive in terms of money and time and so it is impossible to graduate a large number of potential biomarkers to a validation phase. Unfortunately, it is difficult to inherently recognize those proteins identified in the discovery phase that may turn out to be the best biomarker. Nevertheless, encouragement can be found in the progress that has been made in the past years, allowing investigators to attempt the types of biomarker studies that are being conducted today (Veenstra, 2007). On the other hand, the current proteomic technology still does not allow studying the full genomic equivalent of all proteins, whereas transcriptome analyses cover the whole genomic sequence and are also able to produce data at a much higher pace. Nevertheless, transcript expression profiling is unable to distinguish between different gene products derived from the same coding region on the genome (due to, e.g., modifications, truncations, or splice variants). It should also be kept in mind that none of these technologies alone will be able to deliver novel drugs.

\section{Outlook}

The genomics revolution has changed the paradigm for the comprehensive analysis of biological processes. The genomic era began in the year 1995 when the first complete bacterial genomic sequence of Haemophilus influenzae was published. Since that moment, a distinct change in the quality of microbial genetic studies can be observed. Analyses of single genes leads presently to global analyses of microbial cells, while analyses of full genetic sequences, whole transcriptomes as well as total protein content or networks of protein-protein interactions is directed to the genome, transcriptome, proteome and interactome, respectively. The word Proteome describes the ensemble of protein forms 
expressed in a biological sample at a given point in time and in a given situation. Proteomics has seen the increasing creation of new useful techniques, but the study of proteomes is still based on 2-DE, allied with MS analysis. Among the proteomic techniques commonly used for analysis of protein expression in biological samples, 2D-PAGE is a popular technique for the separation of proteins. However, 2-DE still has some drawbacks, like excluding the smallest and the largest proteins, those which are extremely acidic and those extremely basic (Gygi et al., 2000). Furthermore, some proteins cannot be detected due to the low sensitivity of the system (Washburn et al., 2001; Wu \& Han, 2006). On the other hand, there are certain limitations to the universal use of this technology, such as low detection sensitivity and linearity, poor solubility of membrane proteins, limited loading capacity of gradient $\mathrm{pH}$ strips, gel reproducibility, relatively low throughput and low linear range of visualisation procedures (López et al., 2004). RNA profiling, which is capable of addressing the expression of all genes in an organism, can be used to complement proteome analysis. An increase in sensitivity can be achieved through modifications or additions to the common proteomic methods. Loading higher amounts of proteins onto a 2-DE gel can help in the identification of low-expressed proteins, despite the fact that, in this case, these can be "hidden" by high-abundance proteins. Also, the use of different protein extraction buffers and detergents can improve the sensitivity and resolution of the 2-DE profiles. IPG strips provide reproducibility, increased resolution and loading capacity and simplicity to isoelectric focusing of 2-DE. With this technique, a higher number of different proteins can be resolved where previously a single spot was present in the gel (Fey \& Larsen, 2001; Wildgruber et al., 2000). Non-equilibrium pH gel electrophoresis (NEPHGE) is another method that allows a better resolution of protein spots; the resulting peptides are then separated through multi-dimensional chromatography and analyzed using tandem-MS, and if combined with stable isotope labeling experiment methods, it can be a very powerful tool for proteome characterization. Protein arrays and antibody microarrays can create proteomic maps, revealing the proteome (Souza et al., 2008; Wingren \& Borrebaeck, 2004).

Substantial progress has already been made in elucidating the basic regulatory networks that form the basis for the extraordinary capacity of bacteria to adapt to a diversity of lifestyles and external stress factors. A database of these results will be able to facilitate the identification of more comprehensive signatures for treatment with antimicrobial agents and support functional analysis by combined protein and RNA profiling. However, since classical proteomic approaches alone mainly provide information on the relative amounts of protein species and only rarely provides information on the activity of these protein species, it is necessary to complement these findings with metabolomics and interaction studies to determine the true functional level of biological systems. Proteomics and genomics technologies offer more sensitive and specific methods for identification of microbial food contaminants and their toxins. Classical antibiotics are characterized as compounds which influence microbial life processes without harming the host's cells. Their main mechanism of action is based on blocking cell wall synthesis and replication or translation inhibition. Metagenomic techniques, based on direct cloning of DNA present in natural environments, allow the identification of several new antibiotics. The increasing resistance of bacterial pathogens to present day antibiotics and the lack of a robust pipeline of innovative antimicrobial substances demand innovative and more efficient approaches towards the development of anti-infective drugs. 


\section{References}

Ackermann, B. L., Hale, J. E. \& Duffin, K. L. (2006). The Role of Mass Spectrometry in Biomarker Discovery and Measurement. Curr Drug Metab, Vol. 7, No. 5, (Jun, 2006), pp. (525-539), ISSN 1389-2002

Angulo, F., Nargund, V. \& Chiller, T. (2004). Evidence of an association between use of anti-microbial agents in food animals and anti-microbial resistance among bacteria isolated from humans and the human health consequences of such resistance. Journal of Veterinary Medicine B. Infectious Diseases and Veterinary Public Health. No. 51, pp. 374-379

Antunes, P., Machado, J. \& Peixe, L. (2006). Characterization of Antimicrobial Resistance and Class 1 and 2 Integrons in Salmonella Enterica Isolates from Different Sources in Portugal. J Antimicrob Chemother, Vol. 58, No. 2, (Aug, 2006), pp. (297304), ISSN 0305-7453

Apfel, C. M., Locher, H., Evers, S., Takacs, B., Hubschwerlen, C., Pirson, W., Page, M. G. \& Keck, W. (2001). Peptide Deformylase as an Antibacterial Drug Target: Target Validation and Resistance Development. Antimicrob Agents Chemother, Vol. 45, No. 4, (Apr, 2001), pp. (1058-1064), ISSN 0066-4804

Armitage, J. P., Dorman, C. J., Hellingwerf, K., Schmitt, R., Summers, D. \& Holland, B. (2003). Thinking and Decision Making, Bacterial Style: Bacterial Neural Networks, Obernai, France, 7th-12th June 2002. Mol Microbiol, Vol. 47, No. 2, (Jan, 2003), pp. (583-593), ISSN 0950-382X

Bager, F. \& Helmuth, R. (2001). Epidemiology of Resistance to Quinolones in Salmonella. Vet Res, Vol. 32, No. 3-4, (May-Aug, 2001), pp. (285-290), ISSN 0928-4249

Bandow, J. E., Becher, D., Buttner, K., Hochgrafe, F., Freiberg, C., Brotz, H. \& Hecker, M. (2003). The Role of Peptide Deformylase in Protein Biosynthesis: A Proteomic Study. Proteomics, Vol. 3, No. 3, (Mar, 2003), pp. (299-306), ISSN 1615-9853

Bandow, J. E., Brotz, H., Leichert, L. I., Labischinski, H. \& Hecker, M. (2003). Proteomic Approach to Understanding Antibiotic Action. Antimicrob Agents Chemother, Vol. 47, No. 3, (Mar, 2003), pp. (948-955), ISSN 0066-4804

Bjellqvist, B., Ek, K., Righetti, P. G., Gianazza, E., Gorg, A., Westermeier, R. \& Postel, W. (1982). Isoelectric Focusing in Immobilized Ph Gradients: Principle, Methodology and Some Applications. J Biochem Biophys Methods, Vol. 6, No. 4, (Sep, 1982), pp. (317-339), ISSN 0165-022X

Blonder, J., Issaq, H. J. \& Veenstra, T. D. (2011). Proteomic Biomarker Discovery: It's More Than Just Mass Spectrometry. Electrophoresis, Vol. 32, No. 13, (Jun, 2011), pp. (1541-1548), ISSN 1522-2683

Borges-Walmsley, M. I. \& Walmsley, A. R. (2001). The Structure and Function of Drug Pumps. Trends Microbiol, Vol. 9, No. 2, (Feb, 2001), pp. (71-79), ISSN 0966-842X

Brisabois, A., Cazin, I., Breuil, J. \& Collatz, E. (1997). Surveillance of Antibiotic Resistance in Salmonella. Euro Surveill, Vol. 2, No. 3, (Mar, 1997), pp. (19-20), ISSN 1560-7917

Brotz-Oesterhelt, H., Bandow, J. E. \& Labischinski, H. (2005). Bacterial Proteomics and Its Role in Antibacterial Drug Discovery. Mass Spectrom Rev, Vol. 24, No. 4, (Jul-Aug, 2005), pp. (549-565), ISSN 0277-7037 
Calhoun, L. N., Liyanage, R., Lay, J. O., Jr. \& Kwon, Y. M. (2010). Proteomic Analysis of Salmonella Enterica Serovar Enteritidis Following Propionate Adaptation. BMC Microbiol, Vol. 10, No. 2010), pp. (249), ISSN 1471-2180

Chiu, C. H., Tang, P., Chu, C., Hu, S., Bao, Q., Yu, J., Chou, Y. Y., Wang, H. S. \& Lee, Y. S. (2005). The Genome Sequence of Salmonella Enterica Serovar Choleraesuis, a Highly Invasive and Resistant Zoonotic Pathogen. Nucleic Acids Res, Vol. 33, No. 5, 2005), pp. (1690-1698), ISSN 1362-4962

Coldham, N. G., Randall, L. P., Piddock, L. J. \& Woodward, M. J. (2006). Effect of Fluoroquinolone Exposure on the Proteome of Salmonella Enterica Serovar Typhimurium. J Antimicrob Chemother, Vol. 58, No. 6, (Dec, 2006), pp. (1145-1153), ISSN 0305-7453

de Godoy, L. M., Olsen, J. V., Cox, J., Nielsen, M. L., Hubner, N. C., Frohlich, F., Walther, T. C. \& Mann, M. (2008). Comprehensive Mass-Spectrometry-Based Proteome Quantification of Haploid Versus Diploid Yeast. Nature, Vol. 455, No. 7217, (Oct 30, 2008), pp. (1251-1254), ISSN 1476-4687

DelVecchio, V. G., Wagner, M. A., Eschenbrenner, M., Horn, T. A., Kraycer, J. A., Estock, F., Elzer, P. \& Mujer, C. V. (2002). Brucella Proteomes--a Review. Vet Microbiol, Vol. 90, No. 1-4, (Dec 20, 2002), pp. (593-603), ISSN 0378-1135

Deng, W., Liou, S. R., Plunkett, G., 3rd, Mayhew, G. F., Rose, D. J., Burland, V., Kodoyianni, V., Schwartz, D. C. \& Blattner, F. R. (2003). Comparative Genomics of Salmonella Enterica Serovar Typhi Strains Ty2 and Ct18. J Bacteriol, Vol. 185, No. 7, (Apr, 2003), pp. (2330-2337), ISSN 0021-9193

Di Pasqua, R., Mamone, G., Ferranti, P., Ercolini, D. \& Mauriello, G. (2010). Changes in the Proteome of Salmonella Enterica Serovar Thompson as Stress Adaptation to Sublethal Concentrations of Thymol. Proteomics, Vol. 10, No. 5, (Mar, 2010), pp. (1040-1049), ISSN 1615-9861

Dunne, E. F., Fey, P. D., Kludt, P., Reporter, R., Mostashari, F., Shillam, P., Wicklund, J., Miller, C., Holland, B., Stamey, K., Barrett, T. J., Rasheed, J. K., Tenover, F. C., Ribot, E. M. \& Angulo, F. J. (2000). Emergence of Domestically Acquired CeftriaxoneResistant Salmonella Infections Associated with Ampc Beta-Lactamase. JAMA, Vol. 284, No. 24, (Dec 27, 2000), pp. (3151-3156), ISSN 0098-7484

Edwards, R. A., Olsen, G. J. \& Maloy, S. R. (2002). Comparative Genomics of Closely Related Salmonellae. Trends Microbiol, Vol. 10, No. 2, (Feb, 2002), pp. (94-99), ISSN 0966-842X

Encheva, V., Shah, H. N. \& Gharbia, S. E. (2009). Proteomic Analysis of the Adaptive Response of Salmonella Enterica Serovar Typhimurium to Growth under Anaerobic Conditions. Microbiology, Vol. 155, No. Pt 7, (Jul, 2009), pp. (2429-2441), ISSN 1350-0872

Evers, S., Di Padova, K., Meyer, M., Langen, H., Fountoulakis, M., Keck, W. \& Gray, C. P. (2001). Mechanism-Related Changes in the Gene Transcription and Protein Synthesis Patterns of Haemophilus Influenzae after Treatment with Transcriptional and Translational Inhibitors. Proteomics, Vol. 1, No. 4, (Apr, 2001), pp. (522-544), ISSN 1615-9853 
Fey, P. D., Safranek, T. J., Rupp, M. E., Dunne, E. F., Ribot, E., Iwen, P. C., Bradford, P. A., Angulo, F. J. \& Hinrichs, S. H. (2000). Ceftriaxone-Resistant Salmonella Infection Acquired by a Child from Cattle. $N$ Engl J Med, Vol. 342, No. 17, (Apr 27, 2000), pp. (1242-1249), ISSN 0028-4793

Fey, S. J. \& Larsen, P. M. (2001). 2d or Not 2d. Two-Dimensional Gel Electrophoresis. Curr Opin Chem Biol, Vol. 5, No. 1, (Feb, 2001), pp. (26-33), ISSN 1367-5931

Fink, L., Seeger, W., Ermert, L., Hanze, J., Stahl, U., Grimminger, F., Kummer, W. \& Bohle, R. M. (1998). Real-Time Quantitative Rt-Pcr after Laser-Assisted Cell Picking. Nat Med, Vol. 4, No. 11, (Nov, 1998), pp. (1329-1333), ISSN 1078-8956

Gmuender, H., Kuratli, K., Di Padova, K., Gray, C. P., Keck, W. \& Evers, S. (2001). Gene Expression Changes Triggered by Exposure of Haemophilus Influenzae to Novobiocin or Ciprofloxacin: Combined Transcription and Translation Analysis. Genome Res, Vol. 11, No. 1, (Jan, 2001), pp. (28-42), ISSN 1088-9051

Görg, A., Drews, O., Lück, C., Weiland, F. \& Weiss, W. (2009). 2-De with Ipgs. Electrophoresis, Vol. 30, No. S1, 2009), pp. (122-132), ISSN 1522-2683

Gray, C. P. \& Keck, W. (1999). Bacterial Targets and Antibiotics: Genome-Based Drug Discovery. Cell Mol Life Sci, Vol. 56, No. 9-10, (Nov 30, 1999), pp. (779-787), ISSN 1420-682X

Gygi, S. P., Corthals, G. L., Zhang, Y., Rochon, Y. \& Aebersold, R. (2000). Evaluation of Two-Dimensional Gel Electrophoresis-Based Proteome Analysis Technology. Proc Natl Acad Sci U S A, Vol. 97, No. 17, (Aug 15, 2000), pp. (9390-9395), ISSN 0027-8424

Hamacher, M. Eisenacher, M. \& Stephan, C. (2011). Data Mining in Proteomics from Standards to Applications, Springer, ISBN 978-1-60761-986-4, Germany

Han, X., Aslanian, A. \& Yates, J. R., 3rd. (2008). Mass Spectrometry for Proteomics. Curr Opin Chem Biol, Vol. 12, No. 5, (Oct, 2008), pp. (483-490), ISSN 1367-5931

Hecker, M., Antelmann, H., Buttner, K. \& Bernhardt, J. (2008). Gel-Based Proteomics of Gram-Positive Bacteria: A Powerful Tool to Address Physiological Questions. Proteomics, Vol. 8, No. 23-24, (Dec, 2008), pp. (4958-4975), ISSN 1615-9861

Helms, M., Vastrup, P., Gerner-Smidt, P. \& Molbak, K. (2002). Excess Mortality Associated with Antimicrobial Drug-Resistant Salmonella Typhimurium. Emerg Infect Dis, Vol. 8, No. 5, (May, 2002), pp. (490-495), ISSN 1080-6040

Holland, R. D., Wilkes, J. G., Rafii, F., Sutherland, J. B., Persons, C. C., Voorhees, K. J. \& Lay, J. O., Jr. (1996). Rapid Identification of Intact Whole Bacteria Based on Spectral Patterns Using Matrix-Assisted Laser Desorption/Ionization with Timeof-Flight Mass Spectrometry. Rapid Commun Mass Spectrom, Vol. 10, No. 10, 1996), pp. (1227-1232), ISSN 0951-4198

International surveillance network for the enteric infections Salmonella and VTEC O157. 10 January 2008, Available from: http://www.hpa.org.uk/hpa/inter/enternet_ menu.htm

Jindal, T., Mandal, S. N., Kamal, M. R., Das, A. K. \& Karmakar, D. (2011). Occult Mucin Secreting Adenocarcinoma of Gall Bladder with Metastasis to Urinary Bladder. Updates Surg, Vol. No. (Jul 1, 2011), pp. ISSN 2038-131X 
Johnson, S. B., Lissauer, M., Bochicchio, G. V., Moore, R., Cross, A. S. \& Scalea, T. M. (2007). Gene Expression Profiles Differentiate between Sterile Sirs and Early Sepsis. Ann Surg, Vol. 245, No. 4, (Apr, 2007), pp. (611-621), ISSN 0003-4932

Karatzas, K. A., Randall, L. P., Webber, M., Piddock, L. J., Humphrey, T. J., Woodward, M. J. \& Coldham, N. G. (2008). Phenotypic and Proteomic Characterization of Multiply Antibiotic-Resistant Variants of Salmonella Enterica Serovar Typhimurium Selected Following Exposure to Disinfectants. Appl Environ Microbiol, Vol. 74, No. 5, (Mar, 2008), pp. (1508-1516), ISSN 1098-5336

Kim, K., Yang, E., Vu, G. P., Gong, H., Su, J., Liu, F. \& Lu, S. (2010). Mass SpectrometryBased Quantitative Proteomic Analysis of Salmonella Enterica Serovar Enteritidis Protein Expression Upon Exposure to Hydrogen Peroxide. BMC Microbiol, Vol. 10, No. 2010), pp. (166), ISSN 1471-2180

Kim, S. R., Kim, H. T., Park, H. J., Kim, S., Choi, H. J., Hwang, G. S., Yi, J. H., Ryu do, H. \& Kim, K. H. (2009). Fatty Acid Profiling and Proteomic Analysis of Salmonella Enterica Serotype Typhimurium Inactivated with Supercritical Carbon Dioxide. Int J Food Microbiol, Vol. 134, No. 3, (Sep 15, 2009), pp. (190-195), ISSN 1879-3460

Krishnamurthy, T. \& Ross, P. L. (1996). Rapid Identification of Bacteria by Direct MatrixAssisted Laser Desorption/Ionization Mass Spectrometric Analysis of Whole Cells. Rapid Commun Mass Spectrom, Vol. 10, No. 15, 1996), pp. (1992-1996), ISSN 0951-4198

Leverrier, P., Vissers, J. P., Rouault, A., Boyaval, P. \& Jan, G. (2004). Mass Spectrometry Proteomic Analysis of Stress Adaptation Reveals Both Common and Distinct Response Pathways in Propionibacterium Freudenreichii. Arch Microbiol, Vol. 181, No. 3, (Mar, 2004), pp. (215-230), ISSN 0302-8933

Levy, S. B. (2002). Active Efflux, a Common Mechanism for Biocide and Antibiotic Resistance. J Appl Microbiol, Vol. 92 Suppl, No. 2002), pp. (65S-71S), ISSN 13645072

Lipton, M. S., Pasa-Tolic, L., Anderson, G. A., Anderson, D. J., Auberry, D. L., Battista, J. R., Daly, M. J., Fredrickson, J., Hixson, K. K., Kostandarithes, H., Masselon, C., Markillie, L. M., Moore, R. J., Romine, M. F., Shen, Y., Stritmatter, E., Tolic, N., Udseth, H. R., Venkateswaran, A., Wong, K. K., Zhao, R. \& Smith, R. D. (2002). Global Analysis of the Deinococcus Radiodurans Proteome by Using Accurate Mass Tags. Proc Natl Acad Sci U S A, Vol. 99, No. 17, (Aug 20, 2002), pp. (1104911054), ISSN 0027-8424

López, J.A., Bernard, A. \& Albar, J. P. (2004). Protein expression profiling analysis in hematopoietic stem cells: phenotypic characterization of mesenchymal stem cells, In: Biomedical Applications of Proteomics, Sanchez, J. C., Corthals, G. \& Hochstrasser, D. F., pp. (155-171), WILEY-VCH Verlag, Weinheim, Germany.

Lucas, R. L. \& Lee, C. A. (2000). Unravelling the Mysteries of Virulence Gene Regulation in Salmonella Typhimurium. Mol Microbiol, Vol. 36, No. 5, (Jun, 2000), pp. (10241033), ISSN 0950-382X

Mallick, P. \& Kuster, B. (2010). Proteomics: A Pragmatic Perspective. Nat Biotechnol, Vol. 28, No. 7, (Jul, 2010), pp. (695-709), ISSN 1546-1696 
McClelland, M., Sanderson, K. E., Spieth, J., Clifton, S. W., Latreille, P., Courtney, L., Porwollik, S., Ali, J., Dante, M., Du, F., Hou, S., Layman, D., Leonard, S., Nguyen, C., Scott, K., Holmes, A., Grewal, N., Mulvaney, E., Ryan, E., Sun, H., Florea, L., Miller, W., Stoneking, T., Nhan, M., Waterston, R. \& Wilson, R. K. (2001). Complete Genome Sequence of Salmonella Enterica Serovar Typhimurium Lt2. Nature, Vol. 413, No. 6858, (Oct 25, 2001), pp. (852-856), ISSN 0028-0836

McClelland, M., Sanderson, E. K., Porwollik, S., Spieth, J., Clifton, S. W., Fulton, R., Chunyan, W., Wollam, A., Shah, N., Pepin, K., Bhonagiri, V., Nash, W., Johnson, M., Thiruvilangam, P. \& Wilson, R. K. (2007). Submited to the Embl/Genbank/Ddbj Databases. (November, 2007)

Miko, A., Pries, K., Schroeter, A. \& Helmuth, R. (2005). Molecular Mechanisms of Resistance in Multidrug-Resistant Serovars of Salmonella Enterica Isolated from Foods in Germany. J Antimicrob Chemother, Vol. 56, No. 6, (Dec, 2005), pp. (10251033), ISSN 0305-7453

Miller, S. I., Kukral, A. M. \& Mekalanos, J. J. (1989). Atwo-Component Regulatory System (Phop-Phoq) Controls Salmonella Typhimurium Virulence. Proc Natl Acad Sci U S A, Vol. 86, No. 13, 1989), pp. (5054-5058),

Minden, J. (2007). Comparative Proteomics and Difference Gel Electrophoresis. Biotechniques, Vol. 43, No. 6, (Dec, 2007), pp. (739, 741, 743 passim), ISSN 07366205

Mishra, N. (2010). Introduction to Proteomics: Principles and Applications John Wiley \& Sons Inc., ISBN 978-0-471-75402-2,

Musgrove, M. T., Jones, D. R., Northcutt, J. K., Cox, N. A., Harrison, M. A., Fedorka-Cray, P. J. \& Ladely, S. R. (2006). Antimicrobial Resistance in Salmonella and Escherichia Coli Isolated from Commercial Shell Eggs. Poult Sci, Vol. 85, No. 9, (Sep, 2006), pp. (1665-1669), ISSN 0032-5791

Neidhardt, F. C., Ingraham, J. L. \& Schaechter, M. (1990). Physiology of the Bacterial Cell: A Molecular Approach Sunderland, MA: Sinauer Associates Inc, ISBN 0878936084,

O'Connor, C. D., Farris, M., Fowler, R. \& Qi, S. Y. (1997). The Proteome of Salmonella Enterica Serovar Typhimurium: Current Progress on Its Determination and Some Applications. Electrophoresis, Vol. 18, No. 8, (Aug, 1997), pp. (1483-1490), ISSN 0173-0835

O'Farrel, P. H. (1975) High resolution two-dimensional electrophoresis of proteins. J Biological Chemistry, Vol. 250. No. 10, pp. 4007-4021, ISSN 0021-9258

Osman, K. M., Ali, M. M., Radwan, M. I., Kim, H. K. \& Han, J. (2009). Comparative Proteomic Analysis on Salmonella Gallinarum and Salmonella Enteritidis Exploring Proteins That May Incorporate Host Adaptation in Poultry. J Proteomics, Vol. 72, No. 5, (Jul 21, 2009), pp. (815-821), ISSN 1876-7737

Palagi, P. M., Hernandez, P., Walther, D. \& Appel, R. D. (2006). Proteome Informatics I: Bioinformatics Tools for Processing Experimental Data. Proteomics, Vol. 6, No. 20, (Oct, 2006), pp. (5435-5444), ISSN 1615-9853

Parker, C. E., Pearson, T. W., Anderson, N. L. \& Borchers, C. H. (2010). MassSpectrometry-Based Clinical Proteomics--a Review and Prospective. Analyst, Vol. 135, No. 8, (Aug, 2010), pp. (1830-1838), ISSN 1364-5528 
Parkhill, J., Dougan, G., James, K. D., Thomson, N. R., Pickard, D., Wain, J., Churcher, C., Mungall, K. L., Bentley, S. D., Holden, M. T., Sebaihia, M., Baker, S., Basham, D., Brooks, K., Chillingworth, T., Connerton, P., Cronin, A., Davis, P., Davies, R. M., Dowd, L., White, N., Farrar, J., Feltwell, T., Hamlin, N., Haque, A., Hien, T. T., Holroyd, S., Jagels, K., Krogh, A., Larsen, T. S., Leather, S., Moule, S., O'Gaora, P., Parry, C., Quail, M., Rutherford, K., Simmonds, M., Skelton, J., Stevens, K., Whitehead, S. \& Barrell, B. G. (2001). Complete Genome Sequence of a Multiple Drug Resistant Salmonella Enterica Serovar Typhi Ct18. Nature, Vol. 413, No. 6858, (Oct 25, 2001), pp. (848-852), ISSN 0028-0836

Pinto, L., Poeta, P., Vieira, S., Caleja, C., Radhouani, H., Carvalho, C., Vieira-Pinto, M., Themudo, P., Torres, C., Vitorino, R., Domingues, P. \& Igrejas, G. (2010). Genomic and Proteomic Evaluation of Antibiotic Resistance in Salmonella Strains. J Proteomics, Vol. 73, No. 8, (Jun 16, 2010), pp. (1535-1541), ISSN 1876-7737

Qi, S. Y., Moir, A. \& O'Connor, C. D. (1996). Proteome of Salmonella Typhimurium S11344: Identification of Novel Abundant Cell Envelope Proteins and Assignment to a Two-Dimensional Reference Map. J Bacteriol, Vol. 178, No. 16, (Aug, 1996), pp. (5032-5038), ISSN 0021-9193

Radhouani, H., Poeta, P., Pinto, L., Miranda, J., Coelho, C., Carvalho, C., Rodrigues, J., Lopez, M., Torres, C., Vitorino, R., Domingues, P. \& Igrejas, G. (2010). Proteomic Characterization of Vana-Containing Enterococcus Recovered from Seagulls at the Berlengas Natural Reserve, W Portugal. Proteome Sci, Vol. 8, No. 2010), pp. (48), ISSN 1477-5956

Randall, L. P. \& Woodward, M. J. (2002). The Multiple Antibiotic Resistance (Mar) Locus and Its Significance. Res Vet Sci, Vol. 72, No. 2, (Apr, 2002), pp. (87-93), ISSN 0034-5288

Reinhart, K. \& Hartog, C. S. (2010). Biomarkers as a Guide for Antimicrobial Therapy. Int J Antimicrob Agents, Vol. 36 Suppl 2, No. (Dec, 2010), pp. (S17-21), ISSN 1872-7913

Renzone, G., D'Ambrosio, C., Arena, S., Rullo, R., Ledda, L., Ferrara, L. \& Scaloni, A. (2005). Differential Proteomic Analysis in the Study of Prokaryotes Stress Resistance. Ann Ist Super Sanita, Vol. 41, No. 4, 2005), pp. (459-468), ISSN 0021-2571

Rifai, N., Gillette, M. A. \& Carr, S. A. (2006). Protein Biomarker Discovery and Validation: The Long and Uncertain Path to Clinical Utility. Nat Biotechnol, Vol. 24, No. 8, (Aug, 2006), pp. (971-983), ISSN 1087-0156

Rince, A., Uguen, M., Le Breton, Y., Giard, J. C., Flahaut, S., Dufour, A. \& Auffray, Y. (2002). The Enterococcus Faecalis Gene Encoding the Novel General Stress Protein Gsp62. Microbiology, Vol. 148, No. Pt 3, (Mar, 2002), pp. (703-711), ISSN 1350-0872

Roncada, P., Deriu, F., Gaviraghi, A., Martino, P. A. \& Bonizzi, L. (2009). Proteomic Study of Antibiotic Resistance in Escherichia Coli Strains. Vet Res Commun, Vol. 33 Suppl 1, No. (Sep, 2009), pp. (157-160), ISSN 1573-7446

Schroeder, C. M., White, D. G. \& Meng, J. (2004). Retail Meat and Poultry as a Reservoir of Antimicrobial-Resistant Escherichia Coli. Food Microbiology, Vol. No. 21, 2004), pp. (249-255), ISSN 
Seyfarth, A. M., Wegener, H. C. \& Frimodt-Moller, N. (1997). Antimicrobial Resistance in Salmonella Enterica Subsp. Enterica Serovar Typhimurium from Humans and Production Animals. J Antimicrob Chemother, Vol. 40, No. 1, (Jul, 1997), pp. (6775), ISSN 0305-7453

Silbergeld, E. K., Graham, J., Price, L. B. (2008). Industrial Food Animal Production, Antimicrobial Resistance, and Human Health. Annu. Rev. Public Health Vol. 29, pp. (151-69).

Singh, V. K., Jayaswal, R. K. \& Wilkinson, B. J. (2001). Cell Wall-Active Antibiotic Induced Proteins of Staphylococcus Aureus Identified Using a Proteomic Approach. FEMS Microbiol Lett, Vol. 199, No. 1, (May 15, 2001), pp. (79-84), ISSN 0378-1097

Souza, D. M., Oliveira, B. M., Castro-Dias, E., Winck, F. V., Horiuchi, R. S. O., Baldasso, P. A., Caetano, H. T., Pires, N. K. D., Marangoni, S. \& Novello, J. C. (2008). The Untiring Search for the Most Complete Proteome Representation: Reviewing the Methods. Brief Funct Genomic Proteomic, Vol. 7, No. 4, 2008), pp. (312-321)

Stegemann, H. (1970). Proteinfraktionierungienn polyacrylamid und die anwendung auf die genetische analyse bei pflanzen. Angew. Chem. Vol. 82, pp. (640).

Tang, B. M., McLean, A. S., Dawes, I. W., Huang, S. J. \& Lin, R. C. (2009). Gene-Expression Profiling of Peripheral Blood Mononuclear Cells in Sepsis. Crit Care Med, Vol. 37, No. 3, (Mar, 2009), pp. (882-888), ISSN 1530-0293

Taoka, M., Yamauchi, Y., Shinkawa, T., Kaji, H., Motohashi, W., Nakayama, H., Takahashi, N. \& Isobe, T. (2004). Only a Small Subset of the Horizontally Transferred Chromosomal Genes in Escherichia Coli Are Translated into Proteins. Mol Cell Proteomics, Vol. 3, No. 8, (Aug, 2004), pp. (780-787), ISSN 1535-9476

Threlfall, E. J., Rowe, B. \& Ward, L. R. (1993). A comparison of multiple drug resistance in salmonellas from humans and food animals in England and Wales, 1981 and 1990. Epidemiology and Infection, No. 111, pp. 189-197

Threlfall, E. J. (2002). Antimicrobial Drug Resistance in Salmonella: Problems and Perspectives in Food- and Water-Borne Infections. FEMS Microbiol Rev, Vol. 26, No. 2, (Jun, 2002), pp. (141-148), ISSN 0168-6445

Threlfall, E. J. (2008). Transmission of Antimicrobial-Resistant Salmonella from Food Animals to Humans, Proceedings of Antimicrobial Resistance in Zoonotic Bacteria and Foodborne Pathogens, Washington, DC, June 2008

Tsolis, R. M., Baumler, A. J. \& Heffron, F. (1995). Role of Salmonella Typhimurium MnSuperoxide Dismutase (Soda) in Protection against Early Killing by J774 Macrophages. Infect Immun, Vol. 63, No. 5, (May, 1995), pp. (1739-1744), ISSN 0019-9567

van Leeuwen, W. J., van Embden, J., Guinée, P., Kampelmacher, E. H., Manten, A., van Schothorst, M. (1979). Decrease of drug resistance in salmonella in the Netherlands. Antimicrobial Agentes and Chemotherapy. No. 16, pp. 237-239

van Velkinburgh, J. C. \& Gunn, J. S. (1999). Phop-Phoq-Regulated Loci Are Required for Enhanced Bile Resistance in Salmonella Spp. Infect Immun, Vol. 67, No. 4, (Apr, 1999), pp. (1614-1622), ISSN 0019-9567 
VanBogelen, R. A., Schiller, E. E., Thomas, J. D. \& Neidhardt, F. C. (1999). Diagnosis of Cellular States of Microbial Organisms Using Proteomics. Electrophoresis, Vol. 20, No. 11, (Aug, 1999), pp. (2149-2159), ISSN 0173-0835

Veenstra, T. D. (2007). Global and Targeted Quantitative Proteomics for Biomarker Discovery. J Chromatogr B Analyt Technol Biomed Life Sci, Vol. 847, No. 1, (Feb 15, 2007), pp. (3-11), ISSN 1570-0232

Vihinen, M. (2003). Bioinformatics in Proteomics, In: Handbook of Proteomic Methods, P. Michael Conn, pp. Humana Press Inc.

Võ, A. T. T. (2007). Antibiotic Resistance in Salmonella - Thesis. Ultrecht University

Washburn, M. P., Wolters, D. \& Yates, J. R., 3rd. (2001). Large-Scale Analysis of the Yeast Proteome by Multidimensional Protein Identification Technology. Nat Biotechnol, Vol. 19, No. 3, (Mar, 2001), pp. (242-247), ISSN 1087-0156

Wasinger, V. C., Cordwell, S. J., Cerpa-Poljak, A., Yan, J. X., Gooley, A. A., Wilkins, M. R., Duncan, M. W., Harris, R., Williams, K. L. \& Humphery-Smith, I. (1995). Progress with Gene-Product Mapping of the Mollicutes: Mycoplasma Genitalium. Electrophoresis, Vol. 16, No. 7, (Jul, 1995), pp. (1090-1094), ISSN 0173-0835

Webber, M. A. \& Piddock, L. J. (2003). The Importance of Efflux Pumps in Bacterial Antibiotic Resistance. J Antimicrob Chemother, Vol. 51, No. 1, (Jan, 2003), pp. (911), ISSN 0305-7453

Webber, M. A., Coldham, N. G., Woodward, M. J. \& Piddock, L. J. (2008). Proteomic Analysis of Triclosan Resistance in Salmonella Enterica Serovar Typhimurium. J Antimicrob Chemother, Vol. 62, No. 1, (Jul, 2008), pp. (92-97), ISSN 1460-2091

Westermeier, T. \& Naven, T. (2002). Proteomics in Practice: A Laboratory Manual of Proteome Analysis Wiley

White, D. G., Zhao, S., Sudler, R., Ayers, S., Friedman, S., Chen, S., McDermott, P. F., McDermott, S., Wagner, D. D. \& Meng, J. (2001). The Isolation of AntibioticResistant Salmonella from Retail Ground Meats. N Engl J Med, Vol. 345, No. 16, (Oct 18, 2001), pp. (1147-1154), ISSN 0028-4793

Wildgruber, R., Harder, A., Obermaier, C., Boguth, G., Weiss, W., Fey, S. J., Larsen, P. M. \& Gorg, A. (2000). Towards Higher Resolution: Two-Dimensional Electrophoresis of Saccharomyces Cerevisiae Proteins Using Overlapping Narrow Immobilized Ph Gradients. Electrophoresis, Vol. 21, No. 13, (Jul, 2000), pp. (2610-2616), ISSN 0173-0835

Wingren, C. \& Borrebaeck, C. A. (2004). High-Throughput Proteomics Using Antibody Microarrays. Expert Rev Proteomics, Vol. 1, No. 3, (Oct, 2004), pp. (355-364), ISSN 1744-8387

Winokur, P. L., Brueggemann, A., DeSalvo, D. L., Hoffmann, L., Apley, M. D., Uhlenhopp, E. K., Pfaller, M. A. \& Doern, G. V. (2000). Animal and Human MultidrugResistant, Cephalosporin-Resistant Salmonella Isolates Expressing a PlasmidMediated Cmy-2 Ampc Beta-Lactamase. Antimicrob Agents Chemother, Vol. 44, No. 10, (Oct, 2000), pp. (2777-2783), ISSN 0066-4804

WHO - World Heath Organization, FAO - Food and Agriculture Organization \& OIE The World Organization for Animal Health (2003). Joint FAO/OIE/WHO Expert 
Workshop on Non-Human Antimicrobial Usage and Antimicrobial Resistance: Scientific assessment

WHO - World Health Organization (2005). Drug-resistant Salmonella - Fact Sheet N$^{\circ} 139$

WHO - World Health Organization (2011). Antimicrobial resistance - Fact Sheet No 194

Wu, L. \& Han, D. K. (2006). Overcoming the Dynamic Range Problem in Mass Spectrometry-Based Shotgun Proteomics. Expert Rev Proteomics, Vol. 3, No. 6, (Dec, 2006), pp. (611-619), ISSN 1744-8387

Yao, J. \& Moellering, R. (2003). Antibacterial Agents, In: Manual of Clinical Microbiology, P. Murray, E. Baron, J. Jorgenses, M. Pfaller and R. Yolken, pp. American Society for Microbiology Press, Washington

Zgurskaya, H. I. \& Nikaido, H. (2000). Multidrug Resistance Mechanisms: Drug Efflux across Two Membranes. Mol Microbiol, Vol. 37, No. 2, (Jul, 2000), pp. (219-225), ISSN 0950-382X

Zong, C., Young, G. W., Wang, Y., Lu, H., Deng, N., Drews, O. \& Ping, P. (2008). TwoDimensional Electrophoresis-Based Characterization of Post-Translational Modifications of Mammalian 20s Proteasome Complexes. Proteomics, Vol. 8, No. 23-24, (Dec, 2008), pp. (5025-5037), ISSN 1615-9861 
(C) 2012 The Author(s). Licensee IntechOpen. This is an open access article distributed under the terms of the Creative Commons Attribution 3.0 License, which permits unrestricted use, distribution, and reproduction in any medium, provided the original work is properly cited. 